\title{
Assessing Uncertainties in Estimating Surface Energy Fluxes from Remote Sensing over Natural Grasslands in Brazil
}

Pâmela Suélen Käfer ( $\square$ pamelaskafer@gmail.com )

Universidade Federal do Rio Grande do Sul https://orcid.org/0000-0002-4932-8715

Nájila Souza da Rocha

Universidade Federal do Rio Grande do Sul

Gustavo Pujol Veeck

Universidade Federal de Santa Maria (UFSM)

Lucas Ribeiro Diaz

Universidade Federal do Rio Grande do Sul (UFRGS)

Savannah Tâmara Lemos da Costa

Universidade Federal do Rio Grande do Sul (UFRGS)

\section{Eduardo André Kaiser}

Universidade Federal do Rio Grande do Sul (UFRGS)

\section{Débora Regina Robérti}

Universidade Federal de Santa Maria (UFSM)

Silvia Beatriz Alves Rolim

Universidade Federal do Rio Grande do Sul (UFRGS)

\section{Research Article}

Keywords: Energy balance, Evapotranspiration, Reanalysis data, Eddy covariance, Pampa biome

Posted Date: August 23rd, 2021

DOl: https://doi.org/10.21203/rs.3.rs-374033/v1

License: (1) This work is licensed under a Creative Commons Attribution 4.0 International License. Read Full License

Version of Record: A version of this preprint was published at Theoretical and Applied Climatology on February 12th, 2022. See the published version at https://doi.org/10.1007/s00704-021-03869-6. 
Assessing uncertainties in estimating surface energy fluxes from remote sensing over natural grasslands in Brazil

Pâmela Suélen Käfer ${ }^{a}$ Nájila Souza da Rocha ${ }^{\mathrm{a}}$ Gustavo Pujol Veeck ${ }^{\mathrm{b}}$ Lucas Ribeiro Diaz ${ }^{\mathrm{a}}$ Savannah Tâmara Lemos da Costa ${ }^{\mathrm{a}}$ Eduardo André Kaiser ${ }^{\mathrm{a}}$ Débora Regina Robérti $^{\mathrm{b}}$ and Silvia Beatriz Alves Rolim ${ }^{\mathrm{a}}$

${ }^{a}$ State Research Center for Remote Sensing and Meteorology, Universidade Federal do Rio Grande do Sul (UFRGS), Porto Alegre, Brazil. ${ }^{b}$ Department of Physics, Universidade Federal de Santa Maria (UFSM), Santa Maria, Brazil.

*Corresponding author: Pâmela Suélen Käfer. E-mail: pamelaskafer@gmail.com. ORCID number: 0000-0002-4932-8715 


\title{
Assessing uncertainties in estimating surface energy fluxes from remote sensing over natural grasslands in Brazil
}

\begin{abstract}
Evapotranspiration (ET) is one of the main fluxes in the global water cycle. As the Pampa biome carries a rich biodiversity, accurate information on the ET dynamics is essential to support its proper monitoring and establish conservation strategies. In this context, we assessed an operational methodology based on the S-SEBI model to estimate energy fluxes over the natural grasslands of the Brazilian Pampa between 2014-2019. The S-SEBI is a remote sensing-based ET model that requires a minimum of meteorological inputs, being fully applicable for regions lacking in situ observations. Therefore, we investigated the model performance considering radiation data from both ERA5 reanalysis and Eddy Covariance measurements. Furthermore, comparisons from satellite-based estimates with in situ data were performed with and without energy balance closure (EBC). Results showed that the RMSE is impacted in $0.32 \mathrm{~mm} /$ day when reanalysis data are used, indicating that the meteorological inputs have low sensitivity on daily ET estimates from the S-SEBI model. In contrast, the instantaneous energy balance components are more affected. The strong climate seasonality of the Brazilian Pampa impacts the evaporative fraction, which is more evident in late summer and autumn and may compromise the performance of the model. The effects in the daily ET are lower when in situ data without EBC are considered as ground truth. However, they are less correlated with the remote sensing-based estimates. These insights are useful to monitor water and energy fluxes from local to regional scale and provide the opportunity to capture ET trends over the biome.
\end{abstract}

Keywords: Energy balance, Evapotranspiration, Reanalysis data, Eddy covariance, Pampa biome

\section{Introduction}

Evapotranspiration (ET) is widely used to measure the amounts of total water loss through several key processes between land and the atmosphere (Wang and Dickinson 2012; Dou and Yang 2018). Its prediction plays an important role in drought analysis, climate change studies, water level balance, agricultural and forest meteorology, long-term decision-making in food and water security policies, and optimum allocation of water resources (Valipour et al. 2019). ET can be directly measured by using either lysimeter or water balance approach (Kumar et al. 2011). Nonetheless, these methodologies do not allow estimating the land surface fluxes when dealing with large spatial scales (Chen et al. 2005; Courault et al. 2005). 
Satellite observations have been used for monitoring surface conditions over the last few decades because they provide the potential to bridge the gap between point measurements and larger scale surface processes (Ma et al. 2015), thus supplying the need for accessible data for the regions lacking land measurements (Zhang et al. 2018). In addition, accurate land use maps, and abundant meteorological reference data have considerably improved the ability to obtain remotely sensed ET and its flux components (Webster et al. 2016).

Several models have been developed using information from different sensors and often in conjunction with ancillary surface and atmospheric data for ET estimation (Bastiaanssen et al. 1998; Roerink et al. 2000; Senay et al. 2007; Allen et al. 2007). They usually vary from purely empirical to more physically based techniques derived from the surface energy balance (SEB) equation and the information obtained from relationships between satellite-derived vegetation index and land surface temperature (LST) (Liou and Kar 2014). Some of these methods are dependent on many variables measured in surface weather stations as input data, which might prevent its application in large areas with insufficient weather data measuring stations. In contrast, there are some simplified approaches that adopt assumptions of meteorological parameters (Mutti et al. 2019). These simplifications and multiple representation forms may lead to uncertainties in the estimates generated (Chen et al. 2016). Consequently, an evaluation of the benefits and inadequacies of these approaches is a fundamental step.

The Simplified Surface Energy Balance Index (S-SEBI) model (Roerink et al. 2000) estimates ET as a fraction of available energy (named evaporative fraction), in which maximum and minimum temperatures are determined over dry and wet surface lines drawn in an LST-albedo relationship. The model has been applied by several researches that reported reasonable accuracy (Sobrino et al. 2005, 2007; Fan et al. 2007; Olivera-Guerra et al. 2014; Bhattarai et al. 2016). One of the main advantages of using the LST-albedo relationship is that the albedo is sensitive to the total vegetation cover including green and senescent vegetation (Merlin et al. 2014). Furthermore, the model requires a minimum of meteorological data, being entirely suitable for zones with few or none in situ measurements (Olivera-Guerra et al. 2014).

Quantifying ET in a variety of terrestrial ecosystems is valuable for a better understanding of different surface types, assessment of local to global water balances, and water management of agricultural lands. Moreover, the specific features of each biome are essential to formulate proper conservation strategies, appropriate infrastructure, and to understand the impacts of land use changes in each environment (Oliveira et al. 2017; Wagle et al. 2017). Natural grasslands are fundamental to preserve water 
resources and carbon accumulation in the soil (Moreira et al. 2019) and around the world they cover vast regions including the North American Great Plains, the Eurasian steppes of Russia, China and Mongolia, and the South American Pampas (Chaneton et al. 2012). In Brazilian territory, the Pampa biome represents $2.07 \%$ and is recognized as containing a rich biodiversity characterized by a meadow mosaic, with small scrub vegetation areas and forests (Ruviaro et al. 2016). For conservation purposes, accurate information on its dynamics becomes more relevant to support the proper monitoring of the water and energy fluxes.

Over grasslands and pastures in Florida, USA, Bhattarai et al. (2016) suggested that S-SEBI performance for ET retrieving is comparable to the algorithms Surface Energy Balance Algorithm for Land (SEBAL) and Mapping Evapotranspiration at high Resolution and with Internalized Calibration (METRIC). Similarly, Senkondo et al. (2019) compared daily ET estimates derived from the models Operational Simplified Surface Energy Balance (SSEBop), SEBAL and S-SEBI in eastern Africa. The authors reported that the S-SEBI model exhibited a statistically similar ET as the ensemble mean of all models tested and highlighted that the model can be applied elsewhere, especially where observed meteorological variables are limited.

S-SEBI model has been applied in a large variety of climate conditions. However, a detailed assessment of the S-SEBI model in estimating surface fluxes over natural grasslands has not been well explored, especially considering the uncertainties associated with input data, assumptions made, and initial conditions. Furthermore, there is no consensus on which model performs better under the particular conditions and climate of the Pampa biome. Therefore, the purpose of this paper is to investigate an operation methodology based on the S-SEBI model to accurately estimate the surface energy fluxes over natural grasslands. We established the main advantages and major uncertainty sources of the method and documented how the ET varies seasonally in the humid subtropical climate of the Brazilian Pampa.

\section{Material and methods}

According to Chen et al. (2016) there are three major sources of uncertainties related to surface fluxes: inadequate model structure, model input errors, and poorly defined parameters. We focused on studying these aspects for S-SEBI in order to find its fragilities and establish an operational method for retrieving ET over the Brazilian Pampa grasslands. The summary steps of the study are exhibited in the flowchart (Figure 1).

Figure 1. Flowchart with the main steps of the study. 


\subsection{Study site description}

The Pampa biome is composed of old grasslands and covers an area of $178,243 \mathrm{~km}^{2}$, which includes the whole Uruguay territory, a part of Argentina and about two-thirds of Rio Grande do Sul State in southern Brazil (Overbeck et al. 2007). The vegetation consists of a mosaic dominated by a grassland matrix with occasional forested areas, and is home to one of the greatest diversities of grassland plants in the world (Boldrini 2009). The experimental area of this study $\left(29^{\circ} 43^{\prime} 27.502^{\prime \prime} \mathrm{S} ; 5^{\circ} 45^{\prime} 36.097^{\prime \prime} \mathrm{W} ; 88 \mathrm{~m}\right.$ elevation) is part of the International Long Term Ecological Research (ILTER) network and is located in the Federal University of Santa Maria, covering approximately 24 ha of natural vegetation characteristic of the Pampa biome (Rubert et al. 2018) (Figure 2).

Figure 2. Study area location in Brazil and South America. RGB432 colour composition refers to the Landsat 8 OLI scene from August 2018 Path/Row: 222/081.

In the Pampa biome, cattle production is directly associated to the conservation of its natural grasslands, because it has been carried out for over 300 years and is the central maintainer of Pampa features. These activities are characterized by low environmental impact, with little or no contribution of external input (Viglizzo et al. 2001). Nevertheless, the expansion of the agricultural border together with overgrazing are the most frequent phenomena threatening the Pampa (Oliveira et al. 2017), leading to the loss of soil physical quality and consequent decrease plant diversity (Vargas et al. 2015).

The Pampa biome climate is subtropical humid (Cfa) with hot summers according to the Köppen climate classification system (Maragno et al. 2013). It differs from tropical regions of Brazil in terms of seasonality, which is mainly dominated by solar radiation with regular precipitation rates (Rubert et al. 2018). These characteristics ensure the particular environmental conditions of the Pampa ecosystem. In the summer season the maximum temperature can be higher than $30^{\circ} \mathrm{C}$, whereas the winter is marked by low temperatures and frosts. The annual average temperature varies between $16-18{ }^{\circ} \mathrm{C}$, and the precipitation between 1,500-1,600 $\mathrm{mm}$ (well distributed throughout the year). Moreover, this region is constantly subject to sudden changes in weather caused by the passage of the polar front.

\subsection{Theoretical basis and S-SEBI formulation}

Among the various energy fluxes within the atmosphere and Earth's surface, the knowledge of both sensible and latent heat fluxes is of fundamental importance for numerical modeling of atmospheric and hydrological processes (Gomez et al. 2005; Liou and Kar 2014). The most applied approaches to estimate 
ET from remote sensing observations are based on the simplified form of the SEB equation, which is given as:

$$
R n=G+L E+H
$$

where $R n$ is the surface net radiation $\left(\mathrm{W} \mathrm{m}^{-2}\right), G$ is the soil heat flux $\left(\mathrm{W} \mathrm{m}^{-2}\right)$ and $H$ is the sensible heat flux $\left(\mathrm{W} \mathrm{m}^{-2}\right)$ and $L E$ is the latent heat flux of evaporation due to ET $\left(\mathrm{W} \mathrm{m}^{-2}\right)$. ET in volume units can be computed from $L E$ by the amount of energy needed to evaporate water at a specific temperature and (Glenn et al. 2010). $L E$ is estimated as a residual according to:

$$
L E=R n-G-H
$$

The $R n$ can be obtained from remote sensing data according to the following equation (Hurtado and Sobrino 2001):

$$
R n=(1-\alpha) R_{s}+\varepsilon R_{l d}-\varepsilon \sigma T_{s}^{4}
$$

where $R_{s}$ is the shortwave downward radiation $\left(\mathrm{W} \mathrm{m}^{-2}\right), R_{l d}$ the longwave downward radiation $\left(\mathrm{W} \mathrm{m} \mathrm{m}^{-2}\right), \alpha$ is the albedo estimated according to Liang (2001), $\varepsilon$ is the land surface emissivity (LSE), $T_{s}$ is the LST in Kelvin $(\mathrm{K})$ and $\sigma=5.67 \times 10^{-8} \mathrm{~W} \mathrm{~m}^{-2} \mathrm{~K}^{-4}$ is the Stefan-Boltzmann constant. $G$ represents the energy used to heat up the soil or energy released due to cooling of soil and is frequently estimated using an empirical relationship between albedo, LST and normalized difference vegetation index (NDVI) (Bastiaanssen 2000):

$$
G=\frac{T s}{\alpha}\left(0.0038 \alpha+0.0074 \alpha^{2}\right)-\left(1-0.98 \mathrm{NDVI}^{4}\right) R n
$$

The LST is a key variable to be retrieved from the TIR data because it reflects the amount of radiation emitted from the surface and subsurface of the earth, and the exchange of energy between the earth surface and atmosphere (Weng et al. 2019). However, atmospheric, angular and emissivity effects have to be compensated in order to acquire reliable estimates (Li et al. 2013). The Split-window (SW) algorithm used in this paper was proposed by Jimenez-Munoz et al. (2014) based on the mathematical structure proposed by Sobrino et al. (1996). Thus, the LST can be computed as

$$
L S T=T i_{s e n}+1.378\left(T i_{s e n}-T j_{s e n}\right)+0.183\left(T i_{s e n}-T j_{s e n}\right)^{2}-0.268+(54.3-2.238 w)(1-\varepsilon)+(-129.2+16.4 w) \Delta \varepsilon
$$

where $T i_{\text {sen }}$ and $T j_{s e n}$ are the at-sensor brightness temperatures at the bands i and j (10 and 11 for Landsat 8) in $\mathrm{K}, \varepsilon$ is the mean LSE, $\varepsilon=0.5(\varepsilon \mathrm{i}+\varepsilon \mathrm{j}), \Delta \varepsilon$ is the LSE difference, $\Delta \varepsilon=(\varepsilon \mathrm{i}-\varepsilon \mathrm{j}), w$ is the total atmospheric water vapor content (in $\mathrm{g} \cdot \mathrm{cm}^{-2}$ ) estimated according to Buck (1981). As a prior knowledge to obtain LST, LSE was calculated from NDVI values according to Sobrino et al. (2008) using the NDVI Threshold Method. 
The S-SEBI model does not require calculation of $H$. On the other hand, the contrast between an albedo-dependent maximum and minimum LST for dry and wet conditions, respectively, is a main base of the model to partition available energy into $H$ and $L E$ fluxes and is used for computing the evaporative fraction $(\Lambda)$. No additional meteorological data is needed if the surface extremes are available on the scene studied (Liou and Kar 2014). In the case of a wet pixel, $H$ is assumed as zero so the maximum $L E$ (LE $\left.E_{\max }\right)$ can be estimated by subtracting $G$ from $R n\left(\mathrm{LE}_{\max }=\mathrm{R}_{\mathrm{n}}-\mathrm{G}\right)$. In contrast, at a dry pixel $H$ is the highest $\left(\mathrm{H}_{\max }\right)$, which can be estimated by subtracting the $G$ from $R n$ (i.e. $\left.\mathrm{H}_{\max }=R n-\mathrm{G}\right)$. Therefore, $\Lambda$ is expressed as:

$$
\Lambda=\frac{T_{H}-T_{S}}{T_{H}-T_{L E}}
$$

where $\mathrm{T}_{\mathrm{H}}$ and $\mathrm{T}_{\mathrm{LE}}$ are the temperatures of the dry and wet conditions in $\mathrm{K}$. Afterwards, the daily $\mathrm{ET}\left(\mathrm{ET}_{\mathrm{day}}\right)$ can be computed assuming that $\Lambda$ is constant for the day under clear-sky conditions (Brutsaert and Sugita 1992), whereas the instantaneous $R n$ can be extrapolated to a daily scale using the $\mathrm{C}_{\mathrm{di}}$ ratio. This ratio consists of a relationship between the daily net radiation flux and instantaneous radiation flux $\left(\mathrm{R}_{\mathrm{ni}}\right)$ and depends on the day of year (DOY) (Sobrino et al. 2007; Olivera-Guerra et al. 2014):

$$
E T_{d a y}=86400 \Lambda \frac{C_{d i}-R_{n i}}{\lambda}
$$

where $\lambda$ is the latent heat of water vaporization $\left(2450 \mathrm{~J} \mathrm{~g}^{-1}\right)$.

\subsection{Data collection and pre-processing}

\subsubsection{In situ flux data}

Eddy covariance (EC) measurements have been used as the typical reference data for validating several ET estimates at the site and pixel level scales (Numata et al. 2017; Li et al. 2018). EC data over the study site were acquired from a flux tower installed at $29.725^{\circ} \mathrm{S} ; 53.760^{\circ} \mathrm{W}$ (Figure 2). The sensor set in the flux tower included a 3D sonic anemometer (Wind Master Pro; Gill Instruments, Hampshire, UK) to measure wind and air temperature components and a gas analyzer (LI7500, LI-COR Inc., Lincoln, USA) to measure $\mathrm{H}_{2} \mathrm{O} / \mathrm{CO}_{2}$ concentrations at $3 \mathrm{~m}$ high of the surface and $10 \mathrm{~Hz}$ frequency, until June 15, 2016. After this period, the gas analyzer and the anemometer were replaced by the sensor Integrated $\mathrm{CO}_{2}$ and $\mathrm{H}_{2} \mathrm{O}$ OpenPath Gas Analyzer and a 3D Sonic Anemometer (IRGASON, Campbell Scientific Inc., Logan, USA).

Along with the flux tower, sensors installed at $3 \mathrm{~m}$ high measured the total $R_{s}$ (also defined as global radiation) and $\mathrm{R}_{\mathrm{dl}}(\mathrm{CMB} 6, \mathrm{Kipp} \& Z$ Znen, Delft, The Netherlands), $R n$ (NR LITE, Kipp\&Zonen, Delft, The Netherlands), LST (STP01 Hukseflux Thermal Sensors B.V., Delft, The Netherlands) and $G$ at 
depths of 0.10 m (HFP01SC-L; Hukseflux Thermal Sensors B.V., Delft, The Netherlands). The EddyPro Advanced software (version 5.1, LI-COR) was used to process the $L E$ and $H$ heat flux data over half-hour time scales (For detail configurations see Rubert et al. (2018). No gap filling was performed. The EC data footprint analyses indicate that about $90 \%$ of the flux originated within a circle with a radius of $115 \mathrm{~m}$ centered in the flux tower.

Previous studies have reported energy balance closure (EBC) problems in EC data due to the systematic biases in instruments, energy sources not considered and losses of turbulent fluxes at high and low frequencies (Twine et al. 2000; Anderson et al. 2008; Tang et al. 2013). A common approach to correct the error is to maintain a constant Bowen-ratio $(\beta)$ when closing the energy balance (Twine et al. 2000; Wilson et al. 2002; Costa et al. 2010). Thus, the EBC can be forced by using:

$$
\begin{gathered}
\beta=\frac{H}{L E} \\
H_{E B C}=\frac{\beta(R n-G)}{1+\beta} \\
L E_{E B C}=\frac{R n-G}{1+\beta}
\end{gathered}
$$

where $H$ and $L E$ are the sensible and the latent heat flux, respectively $\left(\mathrm{W} \mathrm{m}^{-2}\right)$, and $R n$ is the surface net radiation $\left(\mathrm{W} \mathrm{m}^{-2}\right)$. Because there is no consensus about reconciling the surface energy imbalance measured by the EC system (Tang et al. 2013), the daily comparisons from satellite data with in situ EC measurements were performed both with and without EBC. To obtain the in situ daily ET (ET in situ with EBC), the corrected $L E\left(L E_{E B C}\right)$ in units of $\mathrm{W} \mathrm{m}^{-2}$ was converted to $\mathrm{mm} /$ day using the factor 0.0353 . We assessed flux data between 2014-2019, which included only dates with no clouds over the study site mask. Furthermore, only days with less than $2 \mathrm{~h}$ missing half-hours data were considered when Landsat- 8 OLI/TIRS products were available.

\subsubsection{Reanalysis data}

Uncertainties of coarse reanalysis data may impact the quality of the derived ET (Vinukollu et al. 2011; Badgley et al. 2015). To evaluate the meteorological inputs for the model, we were acquired from the ECMWF ERA5 reanalysis dataset (Hersbach 2016). The product represents the fifth ECMWF reanalysis generation for the global climate and weather and was obtained at a spatial resolution of $0.25^{\circ} \times 0.25^{\circ}$ and hourly temporal resolution. The inputs employed included hourly the average of $R_{s}$ and $R_{l d}$ between 13:00 and 14:00 a.m. GMT time in order to match it with the satellite overpass. To obtain daily values the hourly ERA5 data were posteriorly converted through the method previously mentioned (see 2.3.1). 


\subsubsection{Landsat data}

The Landsat program has the longest record of Earth observation from space (Pahlevan et al. 2014), providing about 40-year mission of acquiring global, moderate resolution images of the Earth's surface every 16 days (Barsi et al. 2014; Ke et al. 2015). Landsat 8 satellite is the latest member of Landsat family and carries two sensors, the Operational Land Imager (OLI) and the Thermal Infrared sensor (TIRS). OLI collects data at a $30 \mathrm{~m}$ spatial resolution with eight bands located in the visible, near-infrared (NIR), and in the shortwave infrared regions of the electromagnetic spectrum, whereas TIRS measures the thermal radiance at $100 \mathrm{~m}$ spatial resolution using two bands located in the atmospheric window between 10 and $12 \mu \mathrm{m}$.

For the previous satellites (Landsat 4, Landsat 5, and Landsat 7) there was only one thermal infrared (TIR) channel. Landsat 8 launch in 2013 was a valuable innovation once its two thermal channels allow the application of the widely known split-window (SW) algorithm to retrieve LST (Jimenez-Munoz et al. 2014) thus providing an opportunity to assess the climate-terrestrial interactions through combinations of both thermal and vegetation remote sensing (Webster et al. 2016). We acquired twentyeighth Landsat 8 scenes between 2014-2019 with clear-sky conditions over the study area from the U.S. Geological Survey website in Level 1 (L1) product. Landsat L1 data are radiometric, geometric, and terraincorrected.

To obtain the normalized difference vegetation index (NDVI) and albedo, Landsat 8 OLI surface reflectance product was also downloaded from the Landsat Data collection. These products are generated at the Earth Resources Observation and Science (EROS). The EROS Science Processing Architecture (ESPA) on-demand interface corrects satellite images for atmospheric effects to create Level-2 data products. The data are generated from the Land Surface Reflectance Code (LaSRC) that uses a unique radiative transfer model (Vermote et al. 2016).

\subsection{Performance metrics}

The image processing was automated through the development of the algorithms in interactive data language (IDL). Ground validation was carried out for the pixel where the tower flux is located (Figure 2). The criteria employed to assess the performances of the flux estimates were the Coefficient of correlation (R), Root Mean Square Error (RMSE) and mean absolute error (MAE). The RMSE is defined by the square root of the sum of the variances and describes the accuracy of estimations, which given as: 


$$
R M S E=\sqrt{\frac{1}{n} \sum_{i=1}^{n}(P i-O i)^{2}}
$$

where $P i$ is a predicted/simulated value, $O i$ is an observed value, and $n$ is the number of observations. The MAE is the average of the absolute difference between the predictions and the observations, defined as:

$$
M A E=\frac{1}{n} \sum_{i=1}^{n}|P i-O i|
$$

\section{Results and discussion}

\subsection{Uncertainties of ERA5 Reanalysis Data}

Measurements of energy radiative fluxes are essential in assessing theoretical treatments of radiative transfer in the atmosphere. ET models usually demonstrate different behavior depending on the meteorological input data used (Badgley et al. 2015). In this section, we evaluated the agreement of ERA5 meteorological reanalysis with the in situ $\mathrm{R}_{\mathrm{s}}$ and $\mathrm{R}_{\mathrm{ld}}$ measured at the flux tower at the Landsat 8 overpass time (Figure 3).

Figure 3. Comparative analysis of the 13:00-14:00h (GMT time) hourly average of (a) downward shortwave radiation $\left(R_{s}\right)$ and $(b)$ downward longwave radiation $\left(R_{l d}\right)$ between ERA5 product and in situ measurements. Shaded areas represent the late autumn and winter seasons.

$\mathrm{R}_{\mathrm{s}}$ determines the surface radiative energy balance during the daytime and significant uncertainties have been reported in its global reanalysis products, which are usually related to the modeling schemes used in the reanalysis systems (Yi et al. 2011). $\mathrm{R}_{\mathrm{s}}$ followed an apparent seasonal pattern, with higher values in warmer seasons and lower in the colder ones, which is directly related to the seasonal difference of solar azimuth angle (Moriwaki and Kanda 2004).

In general, the errors have a similar range during all seasons in which it was found that ERA5 product underestimated the $\mathrm{R}_{\mathrm{s}}$, with RMSE of $69.80 \mathrm{~W} \mathrm{~m}^{-2}$ and MAE of $62.37 \mathrm{~W} \mathrm{~m}^{-2}$ (Figure 3a). Opposite results were found by Tall et al. (2019) that reported that $\mathrm{R}_{\mathrm{s}}$ from ERA5 tended to be overestimated particularly during Monsoon time over Western Africa. Even though, the authors highlighted that ERA5 product has extensive changes compared to the previous product ERA-Interim (such as higher spatial and temporal resolutions and a generally improved representation), because the bias was slightly reduced in that case. Urraca et al. (2018) also compared estimates from ERA5 and ERA-interim products and observed better $R_{\mathrm{S}}$ results with ERA5. 
$\mathrm{R}_{\mathrm{dl}}$ from ERA5 relative to in situ data was also underestimated, but exhibited a less characteristic seasonal pattern compared to $\mathrm{R}_{\mathrm{s}}$. In general, the underestimations are similarly distributed through the year, with RMSE and MAE of $29.11 \mathrm{~W} \mathrm{~m}^{-2}$ and $28.46 \mathrm{~W} \mathrm{~m}^{-2}$, respectively (Figure 3b). It is already documented that the measurement of $\mathrm{R}_{\mathrm{dl}}$ can be dubious (Sugita and Brutsaert 1993; Duarte et al. 2006) mainly because it is greatly influenced by the cloud coverage and water vapor content. In other words, a low ratio of $R_{s}$ at the surface to clear-sky solar radiation indicates the occurrence of clouds, which also means greater $R_{\mathrm{dl}}$ (Yao et al. 2014).

\subsection{Comparison of instantaneous surface energy components}

Figure 4 illustrates the comparisons of instantaneous $G, R n$ and $L E$ estimated from the S-SEBI model (S$\mathrm{SEBI}_{\mathrm{ERA} 5}$ and $\mathrm{S}-\mathrm{SEBI}_{\mathrm{in} \text { situ }}$ ) against ground measurements obtained from $\mathrm{EC}$ data. The tower footprint was utilized to evaluate the performance of the model in comparison to the in situ data at the Landsat 8 overpass.

Figure 4. Comparative analysis of the instantaneous fluxes (a) Soil Heat Flux $(G)$, (b) Radiation Net $(R n)$ and (c) Latent Heat Flux ( $L E)$ between satellite measurements (S-SEBI ERA5 $_{\text {and }}$ S-SEBI in situ $_{\text {) }}$ and field measurements (Fluxes in situ).

$G$ component relative to in situ data was overestimated by both satellite-based measurements (S-SEBI ERA5 and $\mathrm{S}-\mathrm{SEBI}_{\text {in situ }}$ ), and generated very similar correlations. Nonetheless, RMSE and MAE were found to be higher when $G$ was obtained using in situ parameters $\left(\mathrm{S}-\mathrm{SEBI}_{\text {in situ }}\right)$ and produced 54.73 and 52.65 ,

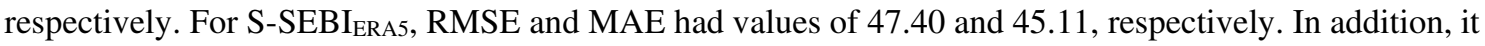
should be noted that $G$ in situ from EC measurements has very low values, reaching negative values in colder periods. Limitations of the empirical formulation used to calculate $G$ from satellite observations were already emphasized (Allies et al. 2020). The $G$ component is commonly sensitive to changes in vegetation cover because as vegetation grows and shades the surface, less incoming solar energy can reach the ground, attenuating the temperature transfer to the soil (Yang et al. 1999; Zimmer et al. 2020). Especially in the Pampa biome, cattle production is associated with the conservation of the grasslands (Oliveira et al. 2017) as part of its natural ecosystem. Therefore, besides the climatic seasonality, the Pampa biomass is directly influenced by the different forms of grazing management to which it is subjected.

The biomass is significantly low in winter when there is less solar radiation available, which clearly affects the components used to calculate $G$ and it results in low values. In addition to LST and albedo, $R n$ is also required in $G$ calculation from remote sensing and this component is dependent on $R_{\mathrm{S}}$ 
and $\mathrm{R}_{\mathrm{dl}}$. As the sum of the incoming and outcoming shortwave and longwave radiations, $R n$ typically achieves its maximum values in summer and minimum in winter (Kofroňová et al. 2019). Rn had a strong correlation for both S-SEBI ERA5 and S-SEBI in situ with values of 0.929 and 0.944, respectively. RMSE and MAE were considerably lower when S-SEBI was running with in situ values $\left(\mathrm{S}-\mathrm{SEBI}_{\mathrm{in}}\right.$ situ), producing 42.48 and 22.65, respectively. On the other hand, for S-SEBI $\mathrm{ERA}_{5}$ both metrics are higher, resulting in 96.31 and 89.01, respectively. These results demonstrate that even considering a more accurate $R n$, a worse $G$ is produced by the model. In other words, $G$ formulation (Eq. 4) is not really sensitive to the $R n$ component, and consequently, $\mathrm{R}_{\mathrm{s}}$ and $\mathrm{R}_{\mathrm{dl}}$.

Table 1. Performance metrics for the modelled energy fluxes using S-SEBI with ERA5 and in situ data. $r$ is the coefficient of correlation (-), RMSE refers to the root-mean-square error $\left(\mathrm{W} \mathrm{m}^{-2}\right)$; and MAE refers to the mean absolute error $\left(\mathrm{W} \mathrm{m}^{-2}\right)$.

$L E$ had correlation coefficients of 0.629 and 0.601 for S-SEBI ERA5 $_{\text {and }}$ S-SEBI in situ, $_{\text {, }}$ respectively. RMSE and MAE were also higher for S-SEBI carried out with in situ data $\left(\mathrm{S}-\mathrm{SEBI}_{\text {in situ }}\right)$, exhibiting values of 93.92

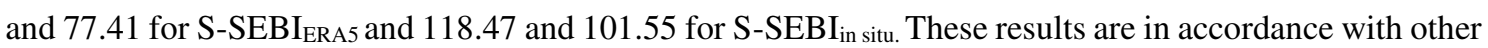
studies performed in the Brazilian Pampa (Schirmbeck et al. 2018; Rocha et al. 2020) and suggest that the instantaneous $L E$ from S-SEBI model can be more affected by other factors (such as the $\Lambda$, obtained from remote sensing through the Eq.6) than $G$ or $R n$, which will be discussed in the next section.

\subsection{Comparison of daily estimates}

The S-SEBI model assumes that $\Lambda$ is stable during the daytime and it is used as a basis to convert the surface energy fluxes from instantaneous to daily (Brutsaert and Sugita 1992). We compared the $\Lambda$ estimated by S-SEBI with $\Lambda$ obtained in situ considering both scenarios with and without EBC (Figure 5). $\Lambda$ in situ was determined from EC measurements by using its general formulation:

$$
\Lambda=\frac{L E}{R n-G}
$$

Figure 5. Comparative analysis of the in situ Evaporative Fraction $(\Lambda)$ (a) with and (b) without Energy Balance Closure (EBC) against $\Lambda$ estimated by S-SEBI model.

According to Farah et al. (2004), the concept of $\Lambda$ cannot be valid under non-clear sky conditions because the diurnal constancy of $\Lambda$ may not be satisfied under cloudy circumstances. Despite the two correlations are weak, regression analysis showed that $\Lambda$ is much more correlated with ET in situ when EBC is 
performed. It indicates that even if the EBC is not properly achieved, using EC data with EBC as ground truth produces better estimates. Zahira et al. (2009) pointed out that errors in the determination of $\mathrm{T}_{\mathrm{H}}$ and $\mathrm{T}_{\mathrm{LE}}$ lines, and consequently in $\Lambda$ (Eq.6), impact the estimation of $L E$. Although the use of the relative diagram LST-albedo to estimate the evaporative regimes can be considered a potential strength of the SSEBI (Mattar et al. 2014), it requires enough wet and dry pixels in the scene for hydrological contrast. Hence, in areas where the relationship is not well correlated, a more sophisticated algorithm may be necessary.

The LST is very important in diagnosing many of the major surface energy balance components, including sensible heat, net radiation, and soil heat flux (Anderson et al. 2012). LST-dependent models assume that ET can cool land surfaces under the condition of homogeneous atmospheric forcing (Sun et al. 2016). Overall, retrieving LST from satellite data with high accuracy has been a research problem at least in the last three decades, especially because of the effects introduced by the atmosphere in the thermal infrared region that must be corrected (Qin et al. 2001; Sobrino et al. 2005; Tardy et al. 2016), otherwise, they may affect the accuracy of both $H$ and $L E$. Uncertainties in LST retrieval algorithms are generally related to the high $w$ content in the atmosphere, and most of them tend to perform badly under conditions of $w>3 \mathrm{~g} . \mathrm{cm}^{-2}$ (Prata 1994). However, the SW algorithm is able to perform well even in conditions of highwater vapor, as already reported by several researchers (Jimenez-Munoz et al. 2014; Yu et al. 2014), which ensures the reliability of the methodology employed. Little has been discussed about the effects of LST accuracy in the ET estimations. Particularly over the Pampa, (Rocha et al. 2020) studied the LST influence in the S-SEBI model between 2015-2019 and found that an error of up to $2 \mathrm{~K}$ in the LST produces an average variation of $0.18 \mathrm{~mm} /$ day. Consequently, the authors concluded that LST itself does not actually influence the average of the retrieved ET (see Rocha et al. (2020) for more extensive discussion).

Besides being the dominant controlling factor of climate and hydrology, ET is one of the main fluxes in the global water cycle. Figure 6 depicts the comparison between daily ET between satellite-based measurements derived from the S-SEBI model (S-SEBI $I_{\text {ERA5 }}$ and $\mathrm{S}-\mathrm{SEBI}_{\text {in situ }}$ ) against field measurements with and without the EBC. Coefficient of correlation was high for both S-SEBI $I_{\text {ERA5 }}$ and S-SEBI $I_{\text {in situ }}$ when compared to in situ data considering EBC (Figure 6a). On the other hand, when contrasted with in situ data without EBC, the correlation did not show significant variations between $\mathrm{S}-\mathrm{SEBI}_{\mathrm{ERA}}$ and $\mathrm{S}-\mathrm{SEBI}_{\text {in situ. }}$ 
Figure 6. Comparative analysis of the Daily Evapotranspiration (ET) between satellite measurements (SSEBI $_{\text {ERA5 }}$ and S-SEBI ${ }_{\text {in situ }}$ ) and field measurements (a) with and (b) without Energy Balance Closure $(\mathrm{EBC})$.

RMSE and MAE had superior agreement with in situ data with EBC than without it, producing 1.38 and 1.12 for $\mathrm{S}-\mathrm{SEBI}_{\mathrm{ERA} 5}$ and 1.06 and 0.79 for $\mathrm{S}-\mathrm{SEBI}_{\mathrm{in} \text { situ, }}$, respectively. In contrast, when considering EC data without EBC as ground truth, the values found were 1.71 and 1.30 for S-SEBI $\mathrm{ERA}_{5}$ and 1.44 and 1.06 for S-

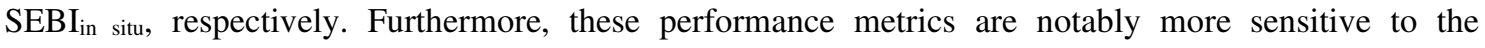
components than the coefficient of correlation that did not have much differences. The results found are in agreement with other validation exercises reported in the literature for the S-SEBI model worldwide (Roerink et al. 2000; Gomez et al. 2005; Verstraeten et al. 2005; Sobrino et al. 2007; Galleguillos et al. 2011). In this context, the Pampa grasslands do not behave so differently from other vegetation types in terms of accuracy of the final daily ET.

Assuming EC data with EBC as ground truth, the RMSE of the daily ET is impacted in 0.32 $\mathrm{mm} /$ day if ERA5 radiation data are used instead of in situ ones. It indicates that the radiation components $\left(\mathrm{R}_{\mathrm{S}}\right.$ and $\mathrm{R}_{\mathrm{dl}}$ ) may play a smaller role in the $\mathrm{S}$-SEBI model. These variations are even less pronounced when EC data without EBC are considered as ground truth, which are affected in $0.27 \mathrm{~mm} / \mathrm{day}$. In general, the use of in situ or ERA5 data as meteorological inputs have low sensitivity on S-SEBI model accuracy to estimate the daily ET over the Brazilian Pampa. Moreover, the results may suggest that when the satellite observations are compared against EC data without EBC, the fact of using reanalysis or in situ radiation data tends to have even lower influence in the daily ET. These findings may be helpful in situations where some of the in situ energy balance components are missing or are not trustable enough to perform a properly EBC.

Table 2. Performance metrics for the modeled daily ET using S-SEBI with ERA5 and in situ parameters. $r$ is the coefficient of correlation (-), RMSE refers to the root-mean-square error (mm/day); and MAE refers to the mean absolute error ( $\mathrm{mm} /$ day).

Transpiration, soil evaporation and interception evaporation components are frequently embedded within remote sensing-based ET models. However, comparisons have demonstrated that although the total evaporative flux from different models agrees relatively well, the different components diverge substantially (Talsma et al. 2018). Even with an instantaneous $G$ and consequently $L E$ less accurate for S$\mathrm{SEBI}_{\text {in situ }}$ in comparison to $\mathrm{S}-\mathrm{SEBI}_{\mathrm{ERA}}$, the use of $\Lambda$ together with the method used for extrapolating from 
instantaneous to daily (Sobrino et al. 2007), clearly contributes to produce more reliable daily ET estimates. Different methods of upscaling of instantaneous ET to daily ET has its own bias (Singh and Senay 2015) and variation depending upon seasonality and cloud conditions. The temporal scaling is usually a weakness of remotely sensed data (Zahira et al. 2009), nevertheless, using radiation data (either from reanalysis or in situ) for this transformation increases the accuracy of the estimates, especially because the global radiation behavior throughout the day is considered.

\subsection{Sazonal and spatial pattern of ET}

Figure 7 shows the seasonal variation of the daily ET between both satellite-based measurements (S$\mathrm{SEBI}_{\mathrm{ERA} 5}$ and $\mathrm{S}-\mathrm{SEBI}_{\text {in situ }}$ ) and field EC data with and without EBC. The daily ET followed a seasonal behavior with the highest values in the summer, period of fast growing for vegetation, and lowest in winter due to the cold weather condition. Over the Pampa the ET is marked by strong seasonality, because it is highly dominated by precipitation rates, which directly affect the partitioning of the turbulent flux (Rubert

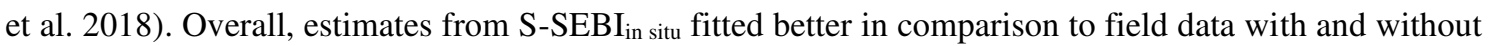

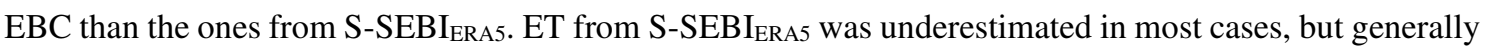
in warmer periods it tended to have better accordance, especially when in situ data with EBC are used as ground truth.

Figure 7. Seasonal pattern of the Daily Evapotranspiration (ET) between satellite measurements (S$\mathrm{SEBI}_{\mathrm{ERA} 5}$ and $\mathrm{S}-\mathrm{SEBI}_{\text {in situ}}$ ) and field measurements with (solid line) and without (dashed line) Energy Balance Closure (EBC). Shaded areas represent the late autumn and winter seasons.

Differences between curves with and without EBC evidenced that measurements with EBC can better capture the variations of the ET seasonal pattern in the natural grasslands of the Pampa biome. Most variations found between ET in situ with and without EBC are seen in late winter and spring seasons, which are noticeable in the DOYs of 202, 266, 278, 282 and 331 (Figure 7). In this context, Rubert et al. (2018) reported that the overestimation of ET from EC data normally occurs in the hydrological regime where water availability is the limiting factor. The authors mentioned that although the relationship between the ET and soil water content depends on soil type, vegetation type, and vegetation adaptation to dryness, the role of soil water content near the surface is expressive. Results indicated that the daily ET from remote sensing observations produced better agreement with in situ EC data in late winter and spring seasons. On the other hand, late summer and autumn exhibited worse estimates. Figure 8 investigates the spatial 
behavior of albedo, LST, $\Lambda$ and daily ET for two different DOYs. The DOY 58 represents a day with less accurate daily ET estimates in late summer, whereas DOY 278 has better daily ET results and is a spring day.

Figure 8. Spatial pattern of the (a) Albedo (-) (b) LST (Kelvin) (c) $\Lambda$ (-) and (d) Daily ET (mm/day) of Pampa biome area for the DOYs 58 and 278. A mask of 150x120 pixels around the flux tower and in situ radiation data were utilized.

Although DOY 278 exhibited a very accurate daily ET estimate, the S-SEBI model underestimated the daily ET for both cases (Figure 8). Differences of 2.26 and $0.2 \mathrm{~mm} /$ day against in situ measurements with $\mathrm{EBC}$, and 3.02 and $0.52 \mathrm{~mm} /$ day in comparison to the in situ measurements without $\mathrm{EBC}$, were founds in the DOYs 58 and 278, respectively. LST and albedo play key roles in the energy balance. Particularly, the lower the albedo is, less solar radiation ends up being reflected back into space, and more is absorbed by the surface, thereby increasing the LST (Findell et al. 2007). Thus, the ET rate increases with the increase of water content in soil due to this lower albedo. It is noticeable that in late summer when the albedo tends to exhibit higher values the opposite is observed. Once the surface reflects more energy strongly reducing the LST, the albedo-LST relationship used in the S-SEBI is compromised, directly affecting $\mathrm{T}_{\mathrm{H}}$ and $\mathrm{T}_{\mathrm{LE}}$ definition, and consequently $\Lambda$ (Eq.6). Thus, the model better represents the pattern of the relationship in spring where the higher data accuracy is seen. Despite the general behavior and accuracy of the S-SEBI in the Pampa biome is not that different from other grassland types, the climate condition commanded by the strong seasonality might prevent the suitable operation of the model in specific DOYs (such as 58), since it directly influences the relationship that is the basis of the model.

\section{Conclusions}

The Pampa biome carries a rich biodiversity and is considered priority for conservation. In this context, accurate information on the ET dynamics is essential to support its proper monitoring. As different remote sensing-based models for ET estimation have different input data requirements, it is fundamental to understand its strength and limitations in addition to comprehend the uncertainties of the components and their impacts on final ET. Because a detailed evaluation of the S-SEBI in retrieving surface fluxes over the natural grasslands of the Pampa has not been properly addressed, we propose to investigate an operation methodology based on the model to estimate the water and energy fluxes. 


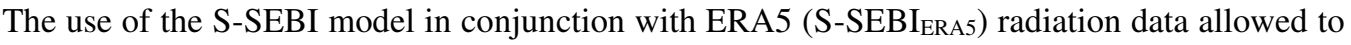
obtain ET over natural grasslands with RMSE and MAE of $1.38 \mathrm{~mm} /$ day and $1.12 \mathrm{~mm} /$ day, respectively. In contrast, by using in situ radiation data as input $\left(\mathrm{S}_{-} \mathrm{SEBI}_{\text {in situ }}\right)$ it produced RMSE and MAE of 1.06mm/day and $0.79 \mathrm{~mm} /$ day, respectively. Thus, the RMSE is impacted in $0.32 \mathrm{~mm} /$ day when reanalysis data are used to replace in situ radiation data, indicating that meteorological inputs have low sensitivity on daily ET estimates by the S-SEBI model. In contrast, the instantaneous components are more affected. The impact in the daily ET is lower when in situ data without EBC are considered as ground truth, despite they are less correlated with the remote sensing-based estimates. It can be helpful particularly when in situ energy balance components are missing and the EBC cannot be properly performed.

Our findings demonstrated that the strong seasonality of the region influences the evaporative fraction, which is the basis of the S-SEBI. This behavior is more evident in late summer and autumn and may compromise the performance of the model. The methodology proposed can guide the generation of accurate long-term records of ET, since the it includes remote sensing products that can be easily obtained for different freely available satellites, such as the Landsat series that provides a continuously acquired collection of data. Moreover, these insights are useful to guide future development and application of remote sensing-based models over grasslands. Therefore, the operational method provides the opportunity to capture ET trends through the time over the natural grasslands of the Brazilian Pampa. Once selecting a model from the wide range available to retrieve ET under a given set of circumstances is challenging for users, in further work we intend to compare S-SEBI performance with other SEB models using the same dataset.

\section{Declarations}

\subsection{Funding}

This study was supported in part by the Coordination for the Improvement of Higher Education Personnel (CAPES), under grant number 88887.467339/2019-00, by the Brazilian National Council for Scientific Research (CNPq) under grant number 141237/2019-8 and the Research Support Foundation of Rio Grande do Sul (FAPERGS). The Landsat-8 OLI/TIRS products are courtesy of the US Geological Survey Earth Resources Observation and Science Center. We are greatful to the Image Processing Laboratory (Global Change Unit) of the Universitat de Valencia (UV), Spain, for providing the S-SEBI model code, especially José Antonio Sobrino and Drazen Skokovic. We are also thankful to the anonymous reviewers for the valuable contributions. 


\subsection{Conflict of interest}

No potential conflict of interest was reported by the authors.

\subsection{Availability of data and material}

Not applicable.

\subsection{Code availability}

Not applicable.

\subsection{Ethics approval}

Not applicable.

\subsection{Consent to participate}

Not applicable.

\subsection{Consent for publication}

All the co-authors are familiar and agree with the content of this paper.

\section{References}

Allen RG, Tasumi M, Trezza R (2007) Satellite-Based Energy Balance for Mapping Evapotranspiration with Internalized Calibration (METRIC)-Model. J Irrig Drain Eng 133:380-394. https://doi.org/10.1061/(ASCE)0733-9437(2007)133:4(380)

Allies A, Demarty J, Olioso A, et al (2020) Evapotranspiration Estimation in the Sahel Using a New Ensemble-Contextual Method. Remote Sens 12:380. https://doi.org/10.3390/rs12030380

Anderson M, Norman J, Kustas W, et al (2008) A thermal-based remote sensing technique for routine mapping of land-surface carbon, water and energy fluxes from field to regional scales. Remote Sens Environ 112:4227-4241. https://doi.org/10.1016/j.rse.2008.07.009

Anderson MC, Allen RG, Morse A, Kustas WP (2012) Use of Landsat thermal imagery in monitoring evapotranspiration and managing water resources. Remote Sens Environ 122:50-65. https://doi.org/10.1016/j.rse.2011.08.025

Badgley G, Fisher JB, Jiménez C, et al (2015) On Uncertainty in Global Terrestrial Evapotranspiration Estimates from Choice of Input Forcing Datasets*. J Hydrometeorol 16:1449-1455. https://doi.org/10.1175/JHM-D-14-0040.1

Barsi J, Schott J, Hook S, et al (2014) Landsat-8 Thermal Infrared Sensor (TIRS) Vicarious Radiometric Calibration. Remote Sens 6:11607-11626. https://doi.org/10.3390/rs61111607

Bastiaanssen WG. (2000) SEBAL-based sensible and latent heat fluxes in the irrigated Gediz Basin, Turkey. J Hydrol 229:87-100. https://doi.org/10.1016/S0022-1694(99)00202-4

Bastiaanssen WGM, Pelgrum H, Wang J, et al (1998) A remote sensing surface energy balance algorithm for land (SEBAL). J Hydrol 212-213:213-229. https://doi.org/10.1016/S0022-1694(98)00254-6

Bhattarai N, Shaw SB, Quackenbush LJ, et al (2016) Evaluating five remote sensing based single-source surface energy balance models for estimating daily evapotranspiration in a humid subtropical climate. Int J Appl Earth Obs Geoinf 49:75-86. https://doi.org/10.1016/j.jag.2016.01.010

Boldrini IIBI (2009) A flora dos campos do Rio Grande do Sul. In: Campos Sulinos. pp 63-67

Brutsaert W, Sugita M (1992) Application of self-preservation in the diurnal evolution of the surface energy budget to determine daily evaporation. J Geophys Res 97:18377. https://doi.org/10.1029/92JD00255

Buck AL (1981) New Equations for Computing Vapor Pressure and Enhancement Factor. J Appl Meteorol 
20:1527-1532. https://doi.org/10.1175/1520-0450(1981)020<1527:NEFCVP>2.0.CO;2

Chaneton EJ, Mazía N, Batista WB, et al (2012) Woody Plant Invasions in Pampa Grasslands: A Biogeographical and Community Assembly Perspective. In: Ecotones Between Forest and Grassland. Springer New York, New York, NY, pp 115-144

Chen JM, Chen X, Ju W, Geng X (2005) Distributed hydrological model for mapping evapotranspiration using remote sensing inputs. J Hydrol 305:15-39. https://doi.org/10.1016/j.jhydrol.2004.08.029

Chen M, Senay GB, Singh RK, Verdin JP (2016) Uncertainty analysis of the Operational Simplified Surface Energy Balance (SSEBop) model at multiple flux tower sites. J Hydrol 536:384-399. https://doi.org/10.1016/j.jhydrol.2016.02.026

Costa MH, Biajoli MC, Sanches L, et al (2010) Atmospheric versus vegetation controls of Amazonian tropical rain forest evapotranspiration: Are the wet and seasonally dry rain forests any different? J Geophys Res 115:G04021. https://doi.org/10.1029/2009JG001179

Courault D, Seguin B, Olioso A (2005) Review on estimation of evapotranspiration from remote sensing data: From empirical to numerical modeling approaches. Irrig Drain Syst 19:223-249. https://doi.org/10.1007/s10795-005-5186-0

Dou X, Yang Y (2018) Evapotranspiration estimation using four different machine learning approaches in different terrestrial ecosystems. Comput Electron Agric 148:95-106. https://doi.org/10.1016/j.compag.2018.03.010

Duarte HF, Dias NL, Maggiotto SR (2006) Assessing daytime downward longwave radiation estimates for clear and cloudy skies in Southern Brazil. Agric For Meteorol 139:171-181. https://doi.org/10.1016/j.agrformet.2006.06.008

Fan L, Liu S, Bernhofer C, et al (2007) Regional land surface energy fluxes by satellite remote sensing in the Upper Xilin River Watershed (Inner Mongolia, China). Theor Appl Climatol 88:231-245. https://doi.org/10.1007/s00704-006-0241-9

Farah HO, Bastiaanssen WGM, Feddes RA (2004) Evaluation of the temporal variability of the evaporative fraction in a tropical watershed. Int $\mathrm{J}$ Appl Earth Obs Geoinf 5:129-140. https://doi.org/10.1016/j.jag.2004.01.003

Findell KL, Shevliakova E, Milly PCD, Stouffer RJ (2007) Modeled Impact of Anthropogenic Land Cover Change on Climate. J Clim 20:3621-3634. https://doi.org/10.1175/JCLI4185.1

Galleguillos M, Jacob F, Prévot L, et al (2011) Comparison of two temperature differencing methods to estimate daily evapotranspiration over a Mediterranean vineyard watershed from ASTER data. Remote Sens Environ 115:1326-1340. https://doi.org/10.1016/j.rse.2011.01.013

Glenn EP, Nagler PL, Huete AR (2010) Vegetation Index Methods for Estimating Evapotranspiration by Remote Sensing. Surv Geophys 31:531-555. https://doi.org/10.1007/s10712-010-9102-2

Gomez M, Olioso A, Sobrino J, Jacob F (2005) Retrieval of evapotranspiration over the Alpilles/ReSeDA experimental site using airborne POLDER sensor and a thermal camera. Remote Sens Environ 96:399-408. https://doi.org/10.1016/j.rse.2005.03.006

Hersbach H (2016) The ERA5 Atmospheric Reanalysis. In: Proceedings of the AGU Fall Meeting Abstracts. pp 12-16

Jimenez-Munoz JC, Sobrino JA, Skokovic D, et al (2014) Land Surface Temperature Retrieval Methods From Landsat-8 Thermal Infrared Sensor Data. IEEE Geosci Remote Sens Lett 11:1840-1843. https://doi.org/10.1109/LGRS.2014.2312032

Ke Y, Im J, Lee J, et al (2015) Characteristics of Landsat 8 OLI-derived NDVI by comparison with multiple satellite sensors and in-situ observations. Remote Sens Environ 164:298-313. https://doi.org/10.1016/j.rse.2015.04.004

Kofroňová J, Tesař M, Šípek V (2019) The influence of observed and modelled net longwave radiation on the rate of estimated potential evapotranspiration. J Hydrol Hydromechanics 67:280-288. https://doi.org/10.2478/johh-2019-0011

Kumar M, Raghuwanshi NS, Singh R (2011) Artificial neural networks approach in evapotranspiration modeling: a review. Irrig Sci 29:11-25. https://doi.org/10.1007/s00271-010-0230-8

Li S, Wang G, Sun S, et al (2018) Assessment of Multi-Source Evapotranspiration Products over China Using Eddy Covariance Observations. Remote Sens 10:1692. https://doi.org/10.3390/rs10111692

Li Z-L, Tang B-H, Wu H, et al (2013) Satellite-derived land surface temperature: Current status and perspectives. Remote Sens Environ 131:14-37. https://doi.org/10.1016/j.rse.2012.12.008

Liang S (2001) Narrowband to broadband conversions of land surface albedo I. Remote Sens Environ 76:213-238. https://doi.org/10.1016/S0034-4257(00)00205-4

Liou Y-A, Kar S (2014) Evapotranspiration Estimation with Remote Sensing and Various Surface Energy Balance Algorithms - A Review. Energies 7:2821-2849. https://doi.org/10.3390/en7052821

Ma N, Zhang Y, Szilagyi J, et al (2015) Evaluating the complementary relationship of evapotranspiration in the alpine steppe of the Tibetan Plateau. Water Resour Res 51:1069-1083. 
https://doi.org/10.1002/2014WR015493

Maragno FP, Santos TG, Cechin SZ (2013) The role of phytophysiognomies and seasonality on the structure of ground-dwelling anuran (Amphibia) in the Pampa biome, southern Brazil. An Acad Bras Cienc 85:1105-1116. https://doi.org/10.1590/S0001-37652013005000042

Mattar C, Franch B, Sobrino JA, et al (2014) Impacts of the broadband albedo on actual evapotranspiration estimated by S-SEBI model over an agricultural area. Remote Sens Environ 147:23-42. https://doi.org/10.1016/j.rse.2014.02.011

Merlin O, Chirouze J, Olioso A, et al (2014) An image-based four-source surface energy balance model to estimate crop evapotranspiration from solar reflectance/thermal emission data (SEB-4S). Agric For Meteorol 184:188-203. https://doi.org/10.1016/j.agrformet.2013.10.002

Moreira A, Bremm C, Fontana DC, Kuplich TM (2019) Seasonal dynamics of vegetation indices as a criterion for grouping grassland typologies. Sci Agric 76:24-32. https://doi.org/10.1590/1678-992x2017-0173

Moriwaki R, Kanda M (2004) Seasonal and Diurnal Fluxes of Radiation, Heat, Water Vapor, and Carbon Dioxide over a Suburban Area. J Appl Meteorol 43:1700-1710. https://doi.org/10.1175/JAM2153.1

Mutti PR, da Silva LL, Medeiros S de S, et al (2019) Basin scale rainfall-evapotranspiration dynamics in a tropical semiarid environment during dry and wet years. Int J Appl Earth Obs Geoinf 75:29-43. https://doi.org/10.1016/j.jag.2018.10.007

Numata I, Khand K, Kjaersgaard J, et al (2017) Evaluation of Landsat-Based METRIC Modeling to Provide High-Spatial Resolution Evapotranspiration Estimates for Amazonian Forests. Remote Sens 9:46. https://doi.org/10.3390/rs9010046

Oliveira TE de, Freitas DS de, Gianezini M, et al (2017) Agricultural land use change in the Brazilian Pampa Biome: The reduction of natural grasslands. Land use policy 63:394-400. https://doi.org/10.1016/j.landusepol.2017.02.010

Olivera-Guerra L, Mattar C, Galleguillos M (2014) Estimation of real evapotranspiration and its variation in Mediterranean landscapes of central-southern Chile. Int J Appl Earth Obs Geoinf 28:160-169. https://doi.org/10.1016/j.jag.2013.11.012

Overbeck G, Muller S, Fidelis A, et al (2007) Brazil's neglected biome: The South Brazilian Campos. Perspect Plant Ecol Evol Syst 9:101-116. https://doi.org/10.1016/j.ppees.2007.07.005

Pahlevan N, Lee Z, Wei J, et al (2014) On-orbit radiometric characterization of OLI (Landsat-8) for applications in aquatic remote sensing. Remote Sens Environ 154:272-284. https://doi.org/10.1016/j.rse.2014.08.001

Prata AJ (1994) Land surface temperature determination from satellites. Adv Sp Res 14:15-26. https://doi.org/10.1016/0273-1177(94)90186-4

Qin Z, Karnieli A, Berliner P (2001) A mono-window algorithm for retrieving land surface temperature from Landsat TM data and its application to the Israel-Egypt border region. Int J Remote Sens 22:3719-3746. https://doi.org/10.1080/01431160010006971

Rocha NS da, Käfer PS, Skokovic D, et al (2020) The Influence of Land Surface Temperature in Evapotranspiration Estimated by the S-SEBI Model. Atmosphere (Basel) 11:1059. https://doi.org/10.3390/atmos11101059

Roerink G., Su Z, Menenti M (2000) S-SEBI: A simple remote sensing algorithm to estimate the surface energy balance. Phys Chem Earth, Part B Hydrol Ocean Atmos 25:147-157. https://doi.org/10.1016/S1464-1909(99)00128-8

Rubert G, Roberti D, Pereira L, et al (2018) Evapotranspiration of the Brazilian Pampa Biome: Seasonality and Influential Factors. Water 10:1864. https://doi.org/10.3390/w10121864

Ruviaro CF, da Costa JS, Florindo TJ, et al (2016) Economic and environmental feasibility of beef production in different feed management systems in the Pampa biome, southern Brazil. Ecol Indic 60:930-939. https://doi.org/10.1016/j.ecolind.2015.08.042

Schirmbeck J, Fontana DC, Roberti DR (2018) Evaluation of OSEB and SEBAL models for energy balance of a crop area in a humid subtropical climate. Bragantia 77:609-621. https://doi.org/10.1590/16784499.2017208

Senay G, Budde M, Verdin J, Melesse A (2007) A Coupled Remote Sensing and Simplified Surface Energy Balance Approach to Estimate Actual Evapotranspiration from Irrigated Fields. Sensors 7:979-1000. https://doi.org/10.3390/s7060979

Senkondo W, Munishi SE, Tumbo M, et al (2019) Comparing Remotely-Sensed Surface Energy Balance Evapotranspiration Estimates in Heterogeneous and Data-Limited Regions: A Case Study of Tanzania’s Kilombero Valley. Remote Sens 11:1289. https://doi.org/10.3390/rs11111289

Singh R, Senay G (2015) Comparison of Four Different Energy Balance Models for Estimating Evapotranspiration in the Midwestern United States. Water 8:9. https://doi.org/10.3390/w8010009

Sobrino JA, Gómez M, Jiménez-Muñoz JC, et al (2005) A simple algorithm to estimate evapotranspiration 
from DAIS data: Application to the DAISEX campaigns. J Hydrol 315:117-125. https://doi.org/10.1016/j.jhydrol.2005.03.027

Sobrino JA, Gómez M, Jiménez-Muñoz JC, Olioso A (2007) Application of a simple algorithm to estimate daily evapotranspiration from NOAA-AVHRR images for the Iberian Peninsula. Remote Sens Environ 110:139-148. https://doi.org/10.1016/j.rse.2007.02.017

Sobrino JA, Jimenez-Munoz JC, Soria G, et al (2008) Land Surface Emissivity Retrieval From Different VNIR and TIR Sensors. IEEE Trans Geosci Remote Sens 46:316-327. https://doi.org/10.1109/TGRS.2007.904834

Sobrino JA, LI Z-L, Stoll MP, Becker F (1996) Multi-channel and multi-angle algorithms for estimating sea and land surface temperature with ATSR data. Int J Remote Sens 17:2089-2114. https://doi.org/10.1080/01431169608948760

Sugita M, Brutsaert W (1993) Cloud effect in the estimation of instantaneous downward longwave radiation. Water Resour Res 29:599-605. https://doi.org/10.1029/92WR02352

Sun Z, Wang Q, Batkhishig O, Ouyang Z (2016) Relationship between Evapotranspiration and Land Surface Temperature under Energy- and Water-Limited Conditions in Dry and Cold Climates. Adv Meteorol 2016:1-9. https://doi.org/10.1155/2016/1835487

Tall M, Albergel C, Bonan B, et al (2019) Towards a Long-Term Reanalysis of Land Surface Variables over Western Africa: LDAS-Monde Applied over Burkina Faso from 2001 to 2018. Remote Sens 11:735. https://doi.org/10.3390/rs11060735

Talsma C, Good S, Miralles D, et al (2018) Sensitivity of Evapotranspiration Components in Remote Sensing-Based Models. Remote Sens 10:1601. https://doi.org/10.3390/rs10101601

Tang R, Li Z-L, Jia Y, et al (2013) Evaluating one- and two-source energy balance models in estimating surface evapotranspiration from Landsat-derived surface temperature and field measurements. Int $\mathbf{J}$ Remote Sens 34:3299-3313. https://doi.org/10.1080/01431161.2012.716529

Tardy B, Rivalland V, Huc M, et al (2016) A Software Tool for Atmospheric Correction and Surface Temperature Estimation of Landsat Infrared Thermal Data. Remote Sens 8:696. https://doi.org/10.3390/rs8090696

Twine TE, Kustas WP, Norman JM, et al (2000) Correcting eddy-covariance flux underestimates over a grassland. Agric For Meteorol 103:279-300. https://doi.org/10.1016/S0168-1923(00)00123-4

Urraca R, Huld T, Gracia-Amillo A, et al (2018) Evaluation of global horizontal irradiance estimates from ERA5 and COSMO-REA6 reanalyses using ground and satellite-based data. Sol Energy 164:339354. https://doi.org/10.1016/j.solener.2018.02.059

Valipour M, Gholami Sefidkouhi MA, Raeini-Sarjaz M, Guzman SM (2019) A Hybrid Data-Driven Machine Learning Technique for Evapotranspiration Modeling in Various Climates. Atmosphere (Basel) 10:311. https://doi.org/10.3390/atmos10060311

Vargas RS, Bataiolli R, da Costa PB, et al (2015) Microbial quality of soil from the Pampa biome in response to different grazing pressures. Genet Mol Biol 38:205-212. https://doi.org/10.1590/S1415475738138120140230

Vermote E, Justice C, Claverie M, Franch B (2016) Preliminary analysis of the performance of the Landsat 8/OLI land surface reflectance product. Remote Sens Environ 185:46-56. https://doi.org/10.1016/j.rse.2016.04.008

Verstraeten WW, Veroustraete F, Feyen J (2005) Estimating evapotranspiration of European forests from NOAA-imagery at satellite overpass time: Towards an operational processing chain for integrated optical and thermal sensor data products. Remote Sens Environ 96:256-276. https://doi.org/10.1016/j.rse.2005.03.004

Viglizzo E., Lértora F, Pordomingo A., et al (2001) Ecological lessons and applications from one century of low external-input farming in the pampas of Argentina. Agric Ecosyst Environ 83:65-81. https://doi.org/10.1016/S0167-8809(00)00155-9

Vinukollu RK, Meynadier R, Sheffield J, Wood EF (2011) Multi-model, multi-sensor estimates of global evapotranspiration: climatology, uncertainties and trends. Hydrol Process 25:3993-4010. https://doi.org/10.1002/hyp.8393

Wagle P, Bhattarai N, Gowda PH, Kakani VG (2017) Performance of five surface energy balance models for estimating daily evapotranspiration in high biomass sorghum. ISPRS J Photogramm Remote Sens 128:192-203. https://doi.org/10.1016/j.isprsjprs.2017.03.022

Wang K, Dickinson RE (2012) A review of global terrestrial evapotranspiration: Observation, modeling, climatology, and climatic variability. Rev Geophys 50:. https://doi.org/10.1029/2011RG000373

Webster E, Ramp D, Kingsford RT (2016) Spatial sensitivity of surface energy balance algorithms to meteorological data in a heterogeneous environment. Remote Sens Environ 187:294-319. https://doi.org/10.1016/j.rse.2016.10.019

Weng Q, Firozjaei MK, Kiavarz M, et al (2019) Normalizing land surface temperature for environmental 
parameters in mountainous and urban areas of a cold semi-arid climate. Sci Total Environ 650:515529. https://doi.org/10.1016/j.scitotenv.2018.09.027

Wilson K, Goldstein A, Falge E, et al (2002) Energy balance closure at FLUXNET sites. Agric For Meteorol 113:223-243. https://doi.org/10.1016/S0168-1923(02)00109-0

Yang Z-L, Dai Y, Dickinson RE, Shuttleworth WJ (1999) Sensitivity of ground heat flux to vegetation cover fraction and leaf area index. J Geophys Res Atmos 104:19505-19514. https://doi.org/10.1029/1999JD900230

Yao Y, Zhao S, Zhang Y, et al (2014) Spatial and Decadal Variations in Potential Evapotranspiration of China Based on Reanalysis Datasets during 1982-2010. Atmosphere (Basel) 5:737-754. https://doi.org/10.3390/atmos5040737

Yi Y, Kimball JS, Jones LA, et al (2011) Evaluation of MERRA Land Surface Estimates in Preparation for the Soil Moisture Active Passive Mission. J Clim 24:3797-3816. https://doi.org/10.1175/2011JCLI4034.1

Yu X, Guo X, Wu Z (2014) Land Surface Temperature Retrieval from Landsat 8 TIRS - Comparison between Radiative Transfer Equation-Based Method, Split Window Algorithm and Single Channel Method. Remote Sens 6:9829-9852. https://doi.org/10.3390/rs6109829

Zahira S, Abderrahmane H, Mederbal K, Frederic D (2009) Mapping Latent Heat Flux in the Western Forest Covered Regions of Algeria Using Remote Sensing Data and a Spatialized Model. Remote Sens 1:795-817. https://doi.org/10.3390/rs1040795

Zhang Z, Gong Y, Wang Z (2018) Accessible remote sensing data based reference evapotranspiration estimation modelling. Agric Water Manag 210:59-69. https://doi.org/10.1016/j.agwat.2018.07.039

Zimmer T, Buligon L, de Arruda Souza V, et al (2020) Influence of clearness index and soil moisture in the soil thermal dynamic in natural pasture in the Brazilian Pampa biome. Geoderma 378:114582. https://doi.org/10.1016/j.geoderma.2020.114582 
Table 1. Performance metrics for the modeled energy fluxes using S-SEBI with ERA5 and in situ data. $\mathrm{r}$ is the coefficient of correlation (-), RMSE refers to the root-mean-square error $\left(\mathrm{W} \mathrm{m}^{-2}\right)$; and MAE refers to the mean absolute error $\left(\mathrm{W} \mathrm{m}^{-2}\right)$.

Table 2. Performance metrics for the modeled daily ET using S-SEBI with ERA5 and in situ parameters. $r$ is the coefficient of correlation (-), RMSE refers to the root-mean-square error (mm/day); and MAE refers to the mean absolute error ( $\mathrm{mm} /$ day).

Figure 1. Flowchart with the main steps of the study.

Figure 2. Study area location in Brazil and South America. RGB432 colour composition refers to the Landsat 8 OLI scene from August 2018 Path/Row: 222/081.

Figure 3. Comparative analysis of the 13:00-14:00h (GMT time) hourly average of (a) downward shortwave radiation $\left(\mathrm{R}_{\mathrm{s}}\right)$ and (b) downward longwave radiation $\left(\mathrm{R}_{\mathrm{ld}}\right)$ between ERA5 product and in situ measurements. Shaded areas represent the late autumn and winter seasons.

Figure 4. Comparative analysis of the instantaneous fluxes (a) Soil Heat Flux (G), (b) Radiation Net (Rn) and (c) Latent Heat Flux $(L E)$ between satellite measurements $\left(\mathrm{S}-\mathrm{SEBI}_{\mathrm{ERA} 5}\right.$ and $\left.\mathrm{S}-\mathrm{SEBI} \mathrm{I}_{\text {in situ }}\right)$ and field measurements (Fluxes in situ).

Figure 5. Comparative analysis of the in situ Evaporative Fraction $(\Lambda)(a)$ with and (b) without Energy Balance Closure (EBC) against $\Lambda$ estimated by S-SEBI model.

Figure 6. Comparative analysis of the Daily Evapotranspiration (ET) between satellite measurements (SSEBI ERA5 $_{\text {and }} \mathrm{S}-\mathrm{SEBI}_{\text {in situ }}$ ) and field measurements (a) with and (b) without Energy Balance Closure (EBC).

Figure 7. Seasonal pattern of the Daily Evapotranspiration (ET) between satellite measurements (S$\mathrm{SEBI}_{\mathrm{ERA} 5}$ and $\mathrm{S}-\mathrm{SEBI}_{\text {in situ }}$ ) and field measurements with (solid line) and without (dashed line) Energy Balance Closure (EBC). Shaded areas represent the late autumn and winter seasons.

Figure 8. Spatial pattern of the (a) Albedo (-) (b) LST (Kelvin) (c) $\Lambda$ (-) and (d) Daily ET (mm/day) of Pampa biome area for the DOYs 58 and 278. A mask of 150x120 pixels around the flux tower and in situ radiation data were utilized. 
Table 1. Performance metrics for the modeled energy fluxes using S-SEBI with ERA5 and in situ data. $r$ is the coefficient of correlation (-), RMSE refers to the root-mean-square error $\left(\mathrm{W} \mathrm{m}^{-2}\right)$; and MAE refers to the mean absolute error $\left(\mathrm{W} \mathrm{m}^{-2}\right)$.

\begin{tabular}{lccr}
\hline Component & R & RMSE & MAE \\
\hline $\mathrm{G}_{\text {ERA5 }}$ & 0.746 & 47.40 & 45.11 \\
$\mathrm{Rn}_{\text {ERA5 }}$ & 0.929 & 96.31 & 89.01 \\
$\mathrm{LE}_{\text {ERA5 }}$ & 0.629 & 93.92 & 77.41 \\
\hline $\mathrm{G}_{\text {in situ }}$ & 0.645 & 54.73 & 52.65 \\
$\mathrm{Rn}_{\text {in situ }}$ & 0.944 & 42.48 & 22.65 \\
$\mathrm{LE}_{\text {in situ }}$ & 0.601 & 118.47 & 101.55 \\
\hline
\end{tabular}


Table 2. Performance metrics for the modeled daily ET using S-SEBI with ERA5 and in situ parameters. $r$ is the coefficient of correlation (-), RMSE refers to the root-mean-square error (mm/day); and MAE refers to the mean absolute error ( $\mathrm{mm} /$ day).

\begin{tabular}{lcrr}
\hline Component & R & RMSE & MAE \\
\hline *ET $_{\text {ERA5 }}$ & 0.834 & 1.38 & 1.12 \\
ET $_{\text {ERA5 }}$ & 0.700 & 1.71 & 1.30 \\
\hline${ }^{* E_{\text {in }} \text { situ }}$ & 0.840 & 1.06 & 0.79 \\
ET $_{\text {in situ }}$ & 0.701 & 1.44 & 1.06 \\
\hline
\end{tabular}

*Refers to the ET compared with EBC. 


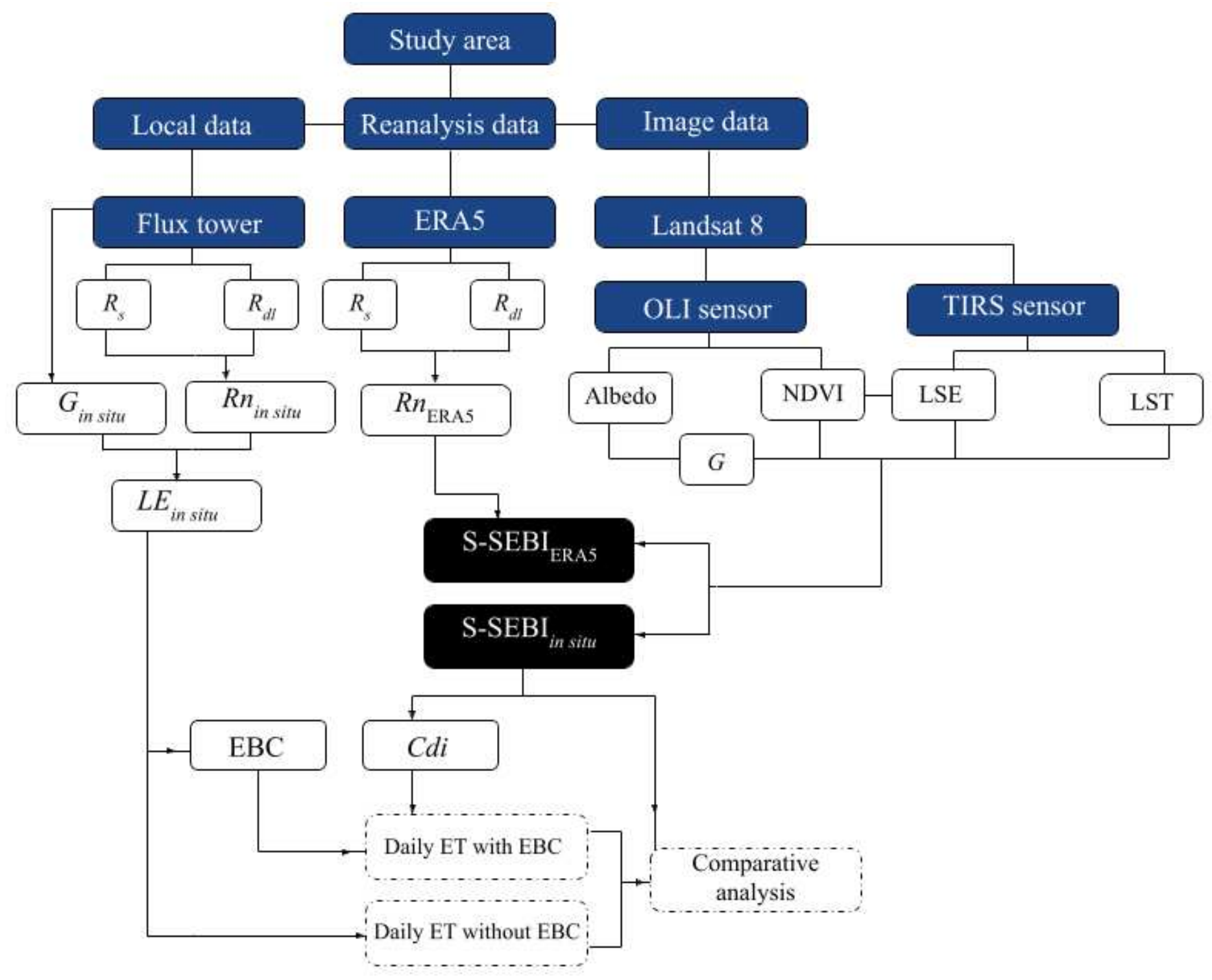

Figure 1

Flowchart with the main steps of the study. 


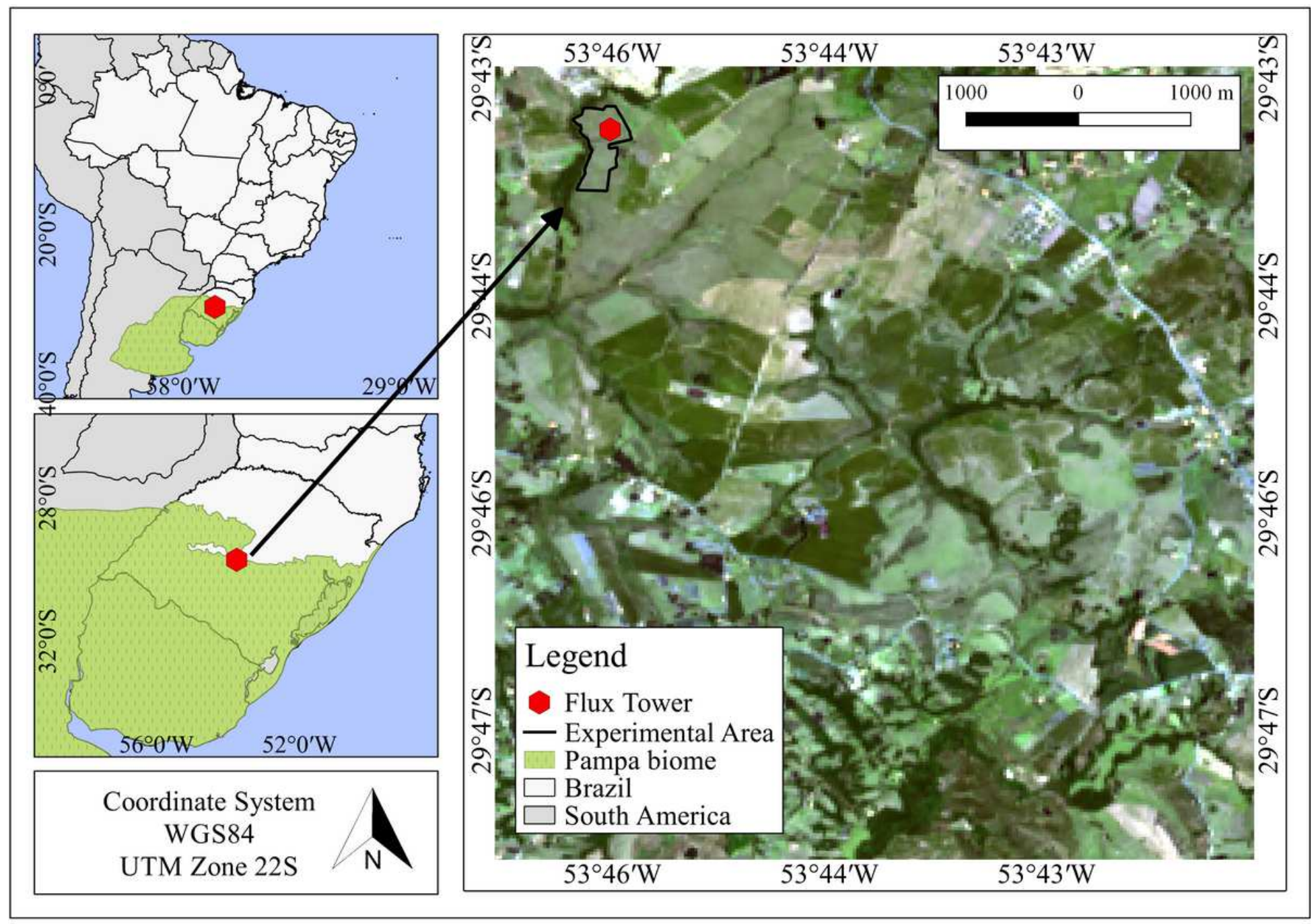

Figure 2

Study area location in Brazil and South America. RGB432 colour composition refers to the Landsat 8 OLI scene from August 2018 Path/Row: 222/081.

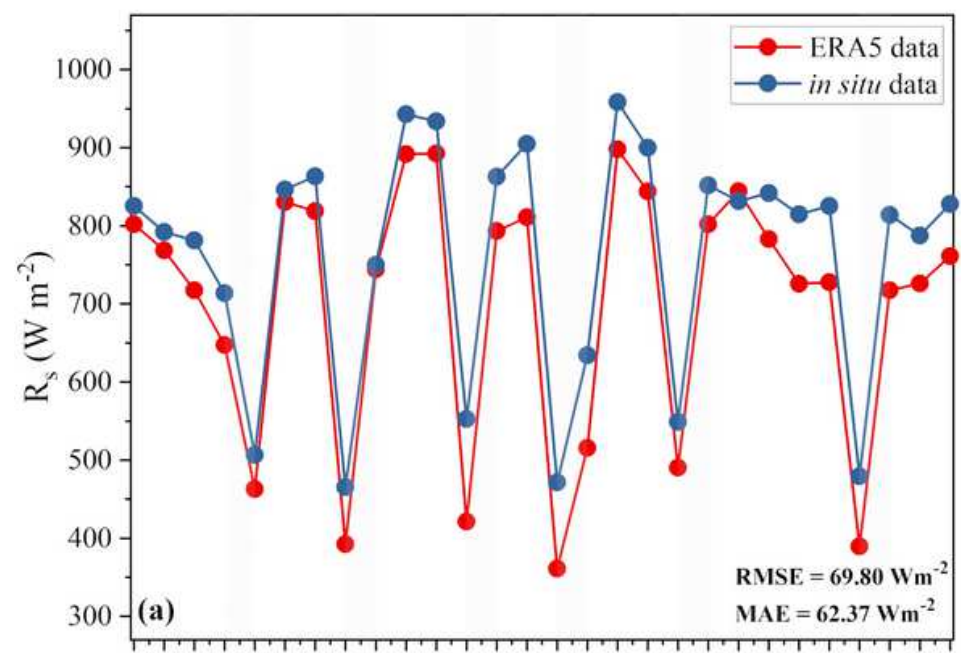

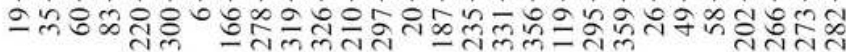
DOY

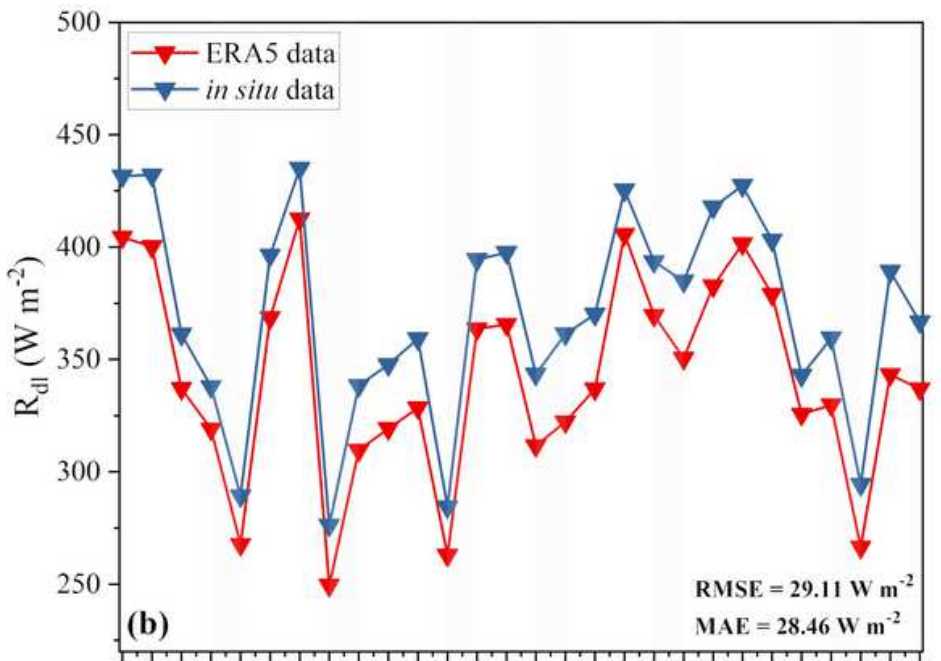

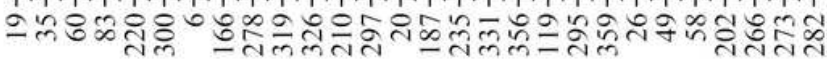
DOY 


\section{Figure 3}

Comparative analysis of the 13:00-14:00h (GMT time) hourly average of (a) downward shortwave radiation (Rs) and (b) downward longwave radiation (RId) between ERA5 product and in situ measurements. Shaded areas represent the late autumn and winter seasons.
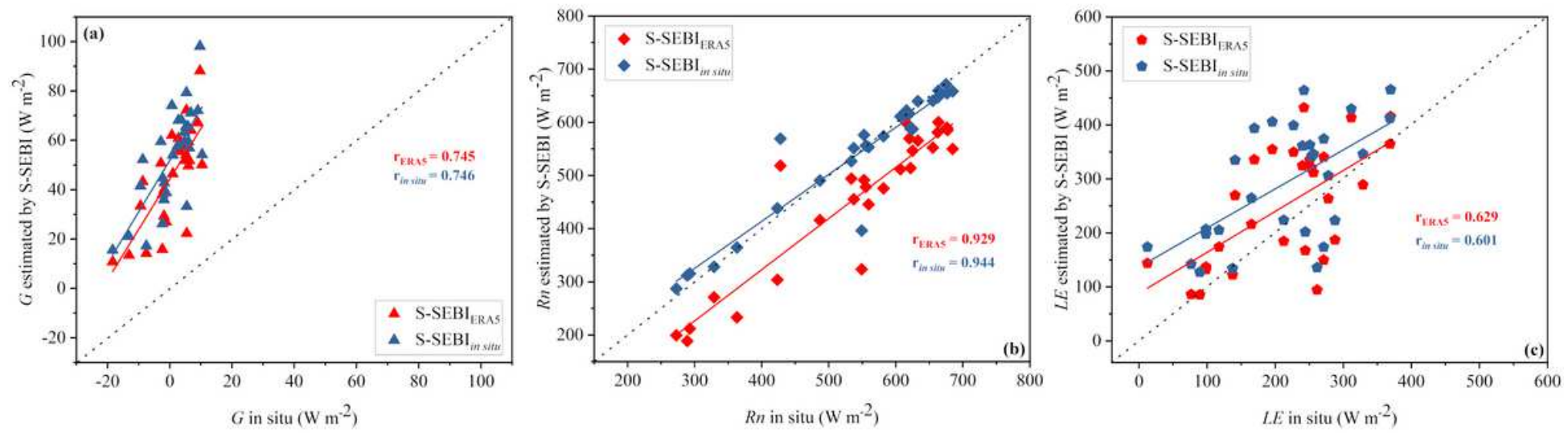

\section{Figure 4}

Comparative analysis of the instantaneous fluxes (a) Soil Heat Flux (G), (b) Radiation Net (Rn) and (c) Latent Heat Flux (LE) between satellite measurements (S-SEBIERA5 and S-SEBlin situ) and field measurements (Fluxes in situ).
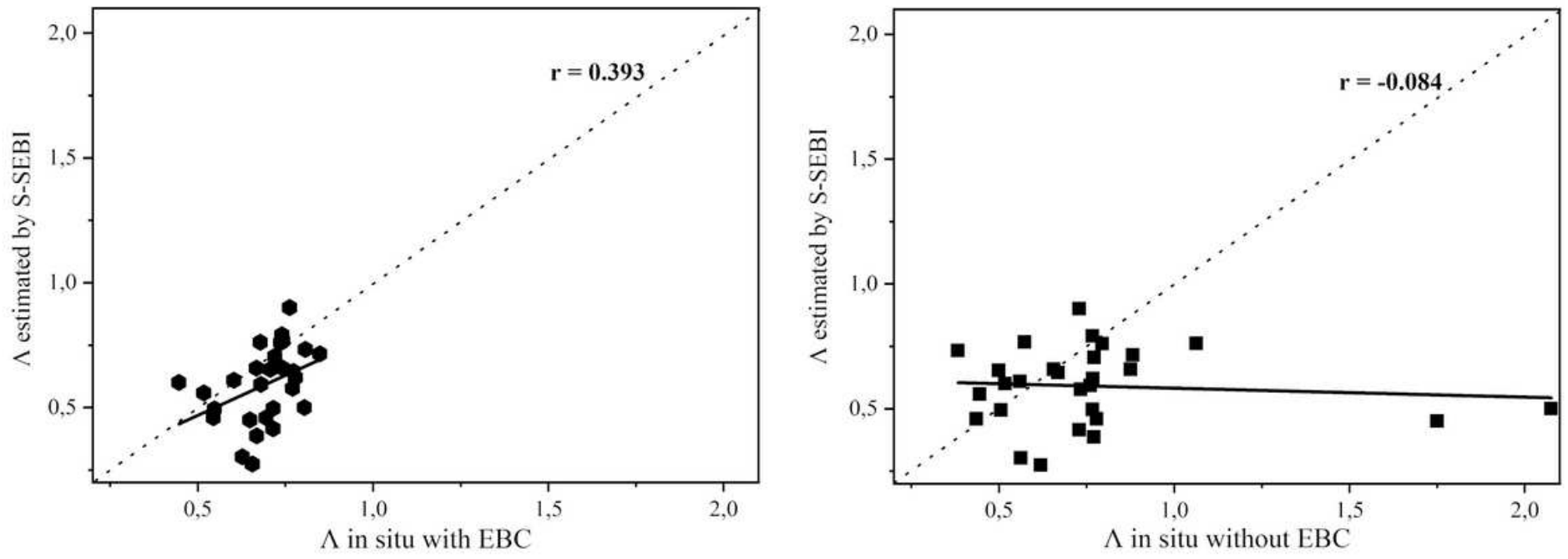

Figure 5

Comparative analysis of the in situ Evaporative Fraction $(\Lambda)(a)$ with and (b) without Energy Balance Closure (EBC) against $\wedge$ estimated by S-SEBI model. 

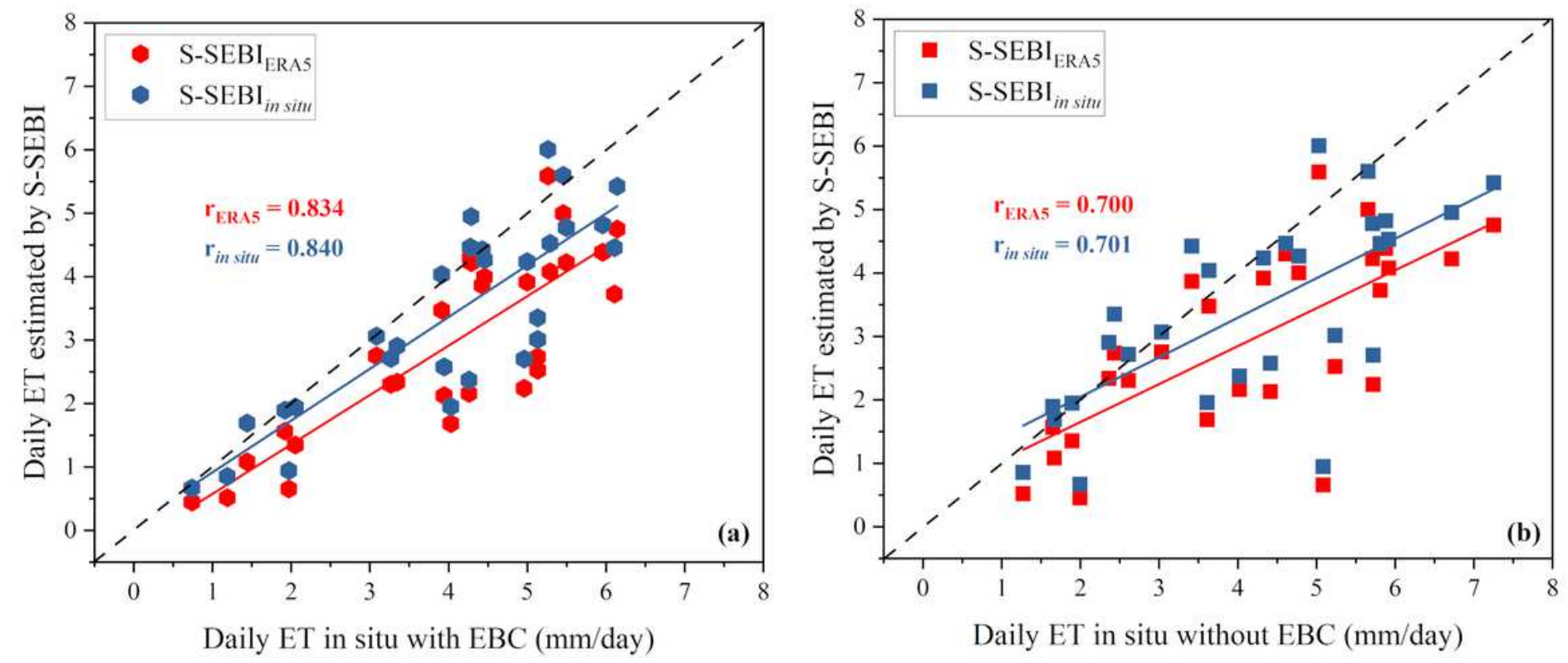

Figure 6

Comparative analysis of the Daily Evapotranspiration (ET) between satellite measurements (S-SEBIERA5 and S-SEBlin situ) and field measurements (a) with and (b) without Energy Balance Closure (EBC). 


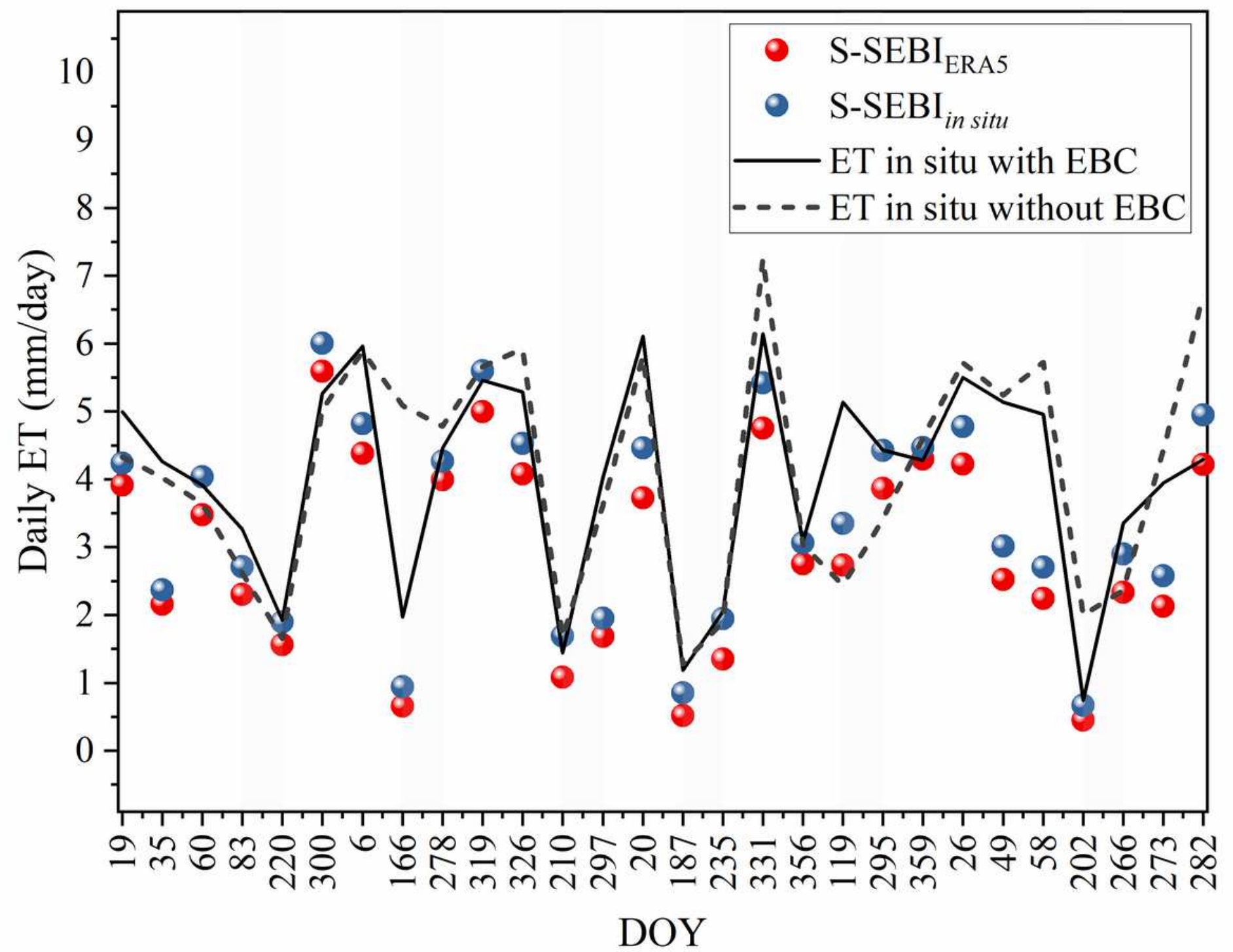

Figure 7

Seasonal pattern of the Daily Evapotranspiration (ET) between satellite measurements (S-SEBIERA5 and S-SEBlin situ) and field measurements with (solid line) and without (dashed line) Energy Balance Closure (EBC). Shaded areas represent the late autumn and winter seasons. 


\section{DOY $58 \quad$ DOY 278}
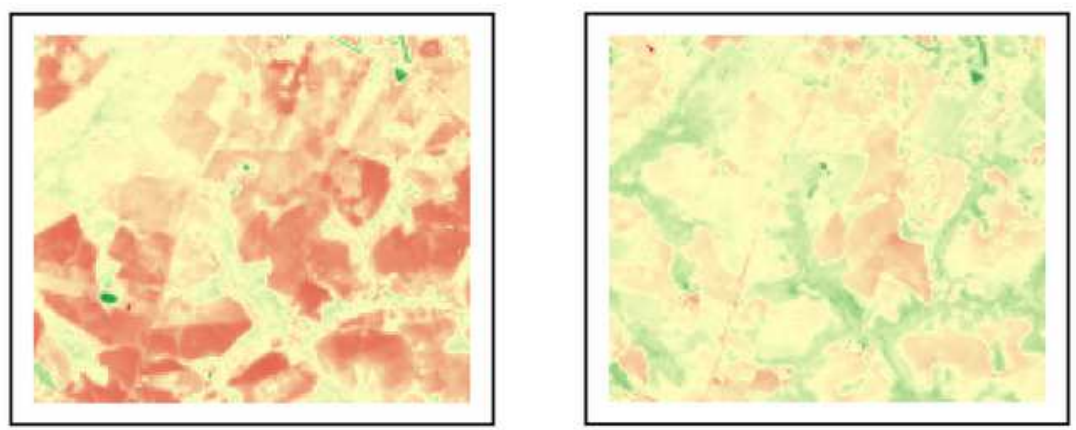

\section{Albedo \\ 0.02 \\ $\square 0.14$ \\ 0.27}
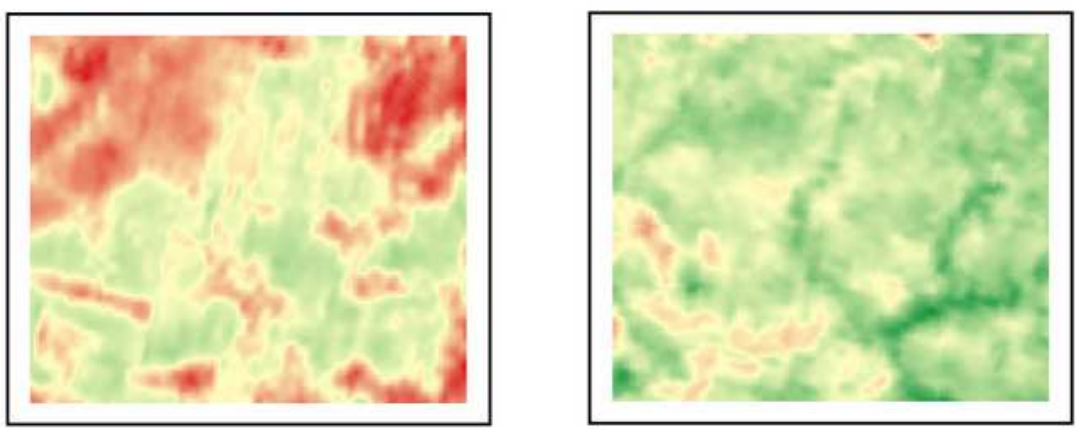

LST

\292.85

$\square 298.02$

$\square$
$\square$
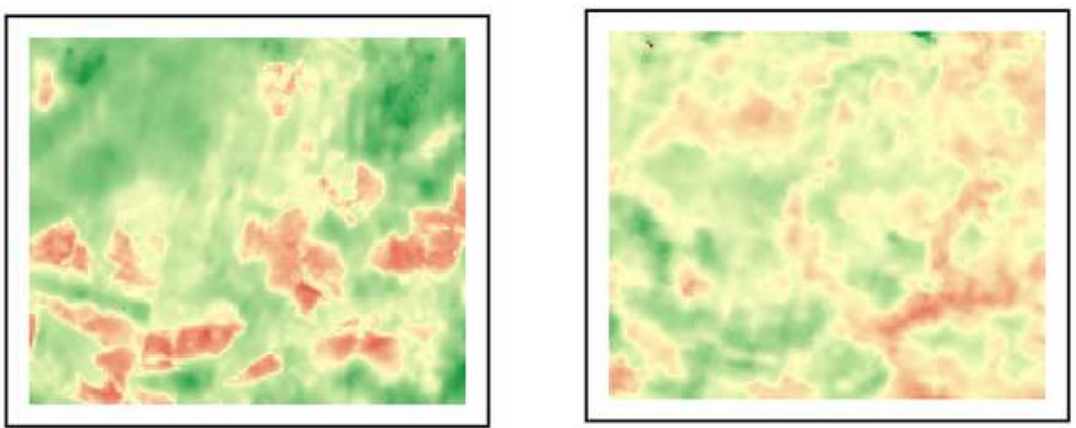

$\Lambda$

0.01

$\square 0.72$

$\square 1.10$
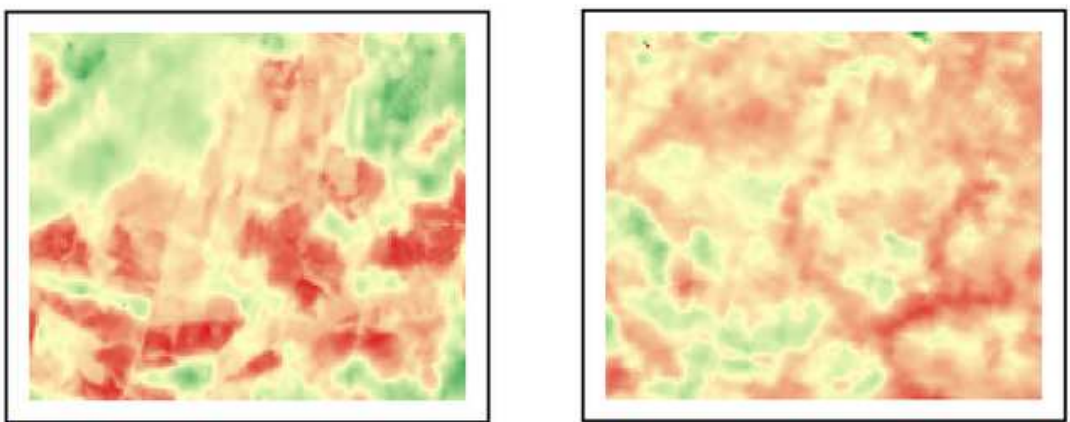

ET/day

1.62

3.49

8.59

\section{Figure 8}

Spatial pattern of the (a) Albedo (-) (b) LST (Kelvin) (c) $\wedge(-)$ and (d) Daily ET (mm/day) of Pampa biome area for the DOYs 58 and 278 . A mask of 150x120 pixels around the flux tower and in situ radiation data were utilized. 